\title{
ZMYM3 regulates BRCA1 localization at damaged chromatin to promote DNA repair
}

\author{
Justin W.C. Leung, ${ }^{1}$ Nodar Makharashvili, ${ }^{1,2}$ Poonam Agarwal, ${ }^{1}$ Li-Ya Chiu, ${ }^{1}$ Renaud Pourpre, ${ }^{1}$ \\ Michael B. Cammarata, ${ }^{3}$ Joe R. Cannon, ${ }^{3}$ Alana Sherker, ${ }^{4}$ Daniel Durocher, ${ }^{4}$ Jennifer S. Brodbelt, ${ }^{3}$ \\ Tanya T. Paull, ${ }^{1,2}$ and Kyle M. Miller ${ }^{1}$ \\ ${ }^{1}$ Department of Molecular Biosciences, The University of Texas at Austin, Austin, Texas 78712, USA; Institute for Cellular \\ and Molecular Biology, The University of Texas at Austin, Austin, Texas 78712, USA; ${ }^{2}$ The Howard Hughes Medical Institute, \\ The University of Texas at Austin, Austin, Texas 78712, USA; ${ }^{3}$ Department of Chemistry, The University of Texas at Austin, \\ Austin, Texas 78712, USA; ${ }^{4}$ The Lunenfeld-Tanenbaum Research Institute, Mount Sinai Hospital, Department of Molecular \\ Genetics, University of Toronto, Toronto, Ontario M5G1X5, Canada
}

\begin{abstract}
Chromatin connects DNA damage response factors to sites of damaged DNA to promote the signaling and repair of DNA lesions. The histone $\mathrm{H} 2 \mathrm{~A}$ variants $\mathrm{H} 2 \mathrm{AX}, \mathrm{H} 2 \mathrm{AZ}$, and macroH2A represent key chromatin constituents that facilitate DNA repair. Through proteomic screening of these variants, we identified ZMYM3 (zinc finger, myeloproliferative, and mental retardation-type 3 ) as a chromatin-interacting protein that promotes DNA repair by homologous recombination (HR). ZMYM3 is recruited to DNA double-strand breaks through bivalent interactions with both histone and DNA components of the nucleosome. We show that ZMYM3 links the HR factor BRCA1 to damaged chromatin through specific interactions with components of the BRCA1-A subcomplex, including ABRA1 and RAP80. By regulating ABRA1 recruitment to damaged chromatin, ZMYM3 facilitates the fine-tuning of BRCA1 interactions with DNA damage sites and chromatin. Consistent with a role in regulating BRCA1 function, ZMYM3 deficiency results in impaired HR repair and genome instability. Thus, our work identifies a critical chromatinbinding DNA damage response factor, ZMYM3, which modulates BRCA1 functions within chromatin to ensure the maintenance of genome integrity.
\end{abstract}

[Keywords: ZMYM3; chromatin; BRCA1-A complex; homologous recombination; DNA repair; DNA damage response] Supplemental material is available for this article.

Received October 21, 2016; revised version accepted January 30, 2017.

Our genetic information is vulnerable to DNA damage, including by replication and exogenous agents. An inability to repair DNA lesions can lead to mutations, chromosome rearrangements, and DNA double-strand breaks (DSBs) that can threaten cellular homeostasis due to genome instability and oncogenic transformation (Aplan 2006; Jackson and Bartek 2009; Ciccia and Elledge 2010). Cells combat these genomic insults through the use of DNA damage response (DDR) pathways (Ciccia and Elledge 2010). For example, DNA DSBs, one of the most deleterious forms of DNA damage, trigger a cascade of events, including localization of DDR factors to sites of lesions, signaling that activates cell cycle checkpoints, and regulation of DNA repair activities. DNA DSBs are primarily repaired by two major pathways: homologous recombination (HR) and nonhomologous end-joining (NHEJ) (Jackson and Bartek 2009). HR preferentially re-

Corresponding author: kyle.miller@austin.utexas.edu Article published online ahead of print. Article and publication date are online at http://www.genesdev.org/cgi/doi/10.1101/gad.292516.116. pairs DSBs in S and G2 phases of the cell cycle, as it uses a template for repair to ensure genome integrity. Alternatively, NHEJ is a process by which two DNA ends are ligated directly at the site of DNA breakage without the engagement of a template, making the process potentially mutagenic (Lieber et al. 2010).

DNA damage recognition, signaling, and repair occur within chromatin (Kim et al. 2007b; Polo and Jackson 2011). Chromatin is composed of nucleosomes consisting of DNA wrapped around histone octamers (Luger et al. 1997). Chromatin structure and dynamics regulate DNA templated cellular processes, including transcription, replication, and DNA repair (Kouzarides 2007). Chromatin structure and function can be modulated by several mechanisms, including histone post-translational

(C) 2017 Leung et al. This article is distributed exclusively by Cold Spring Harbor Laboratory Press for the first six months after the full-issue publication date (see http://genesdev.cshlp.org/site/misc/terms.xhtml). After six months, it is available under a Creative Commons License (Attribution-NonCommercial 4.0 International), as described at http://creativecommons.org/licenses/by-nc/4.0/. 
modifications (PTMs), to promote DSB repair. Upon DNA damage, core histones become modified by several types of PTMs, including phosphorylation, acetylation, methylation, and ubiquitylation (Miller and Jackson 2012). DSB repair uses modifications within chromatin to both promote repair and regulate DSB repair pathway choice. For example, the E3 ubiquitin (Ub) ligase RNF168 ubiquitylates H2A on Lys15 after DNA damage. 53BP1, a repair factor that inhibits HR by antagonizing DNA end resection, binds to both $\mathrm{H} 4 \mathrm{~K} 20 \mathrm{me} 2$ and $\mathrm{H} 2 \mathrm{~A}-\mathrm{Ub}$ at damaged chromatin (Wilson et al. 2016). On the other hand, the E3 Ub ligase BRCA1 ubiquitylates H2A on K127 and K129 to promote HR repair (Kalb et al. 2014). At least four BRCA1-containing complexes have been identified to form ionizing radiation (IR)-induced foci (IRIFs), including BRCA1-A (RAP80/UIMC1，ABRA1/Abraxas/CCDC98, BRCC36, MERIT40/ NBA1, and BRE/BRCC45), whose IRIF formation is regulated by histone ubiquitylation binding by RAP80 (Wu et al. 2009; Li and Greenberg 2012). Tight regulation of these BRCA1 complexes maintains optimal levels of HR-mediated DSB repair. Imbalance of these complexes leads to chromosomal instability and tumorigenesis, including breast and ovarian cancer. The biological importance of the interplay between these pathways in both the DDR and cellular function is highlighted by the finding that deletion of 53BP1 rescues embryonic lethality in BRCA1-deficient mice (Cao et al. 2009; Bouwman et al. 2010; Bunting et al. 2010). Thus, modified chromatin is an integral component of DSB repair that maintains a critical balance between different DSB repair pathways that inhibit cancer and promote genome integrity.

Variants of histone H2A also act as key epigenetic components of chromatin that impact mechanisms that govern both genome and epigenome stability. For example, the histone $\mathrm{H} 2 \mathrm{~A}$ variant $\mathrm{H} 2 \mathrm{AX}$ is phosphorylated on Ser139 $(\gamma \mathrm{H} 2 \mathrm{AX})$ in response to DNA damage, including IR. $\gamma$ H2AX flanks chromosomal DSBs and forms microscopically visible IRIFs (Rogakou et al. 1998, 1999; Stucki and Jackson 2006), which generally serve as beacons to signal the presence of DSBs. A number of DNA repair factors have been shown to form IRIFs and colocalize with $\gamma \mathrm{H} 2 \mathrm{AX}$. Many of them act downstream from $\mathrm{H} 2 \mathrm{AX}$, including MDC1, 53BP1, the MRN complex (MRE11, RAD50 and NBS1), and BRCA1 (Paull et al. 2000; Celeste et al. 2002, 2003). H2AX participates in both NHEJ and HR (Celeste et al. 2002; Xie et al. 2004; Sonoda et al. 2007; Helmink et al. 2011; Zha et al. 2011), and H2AX knockout mice and human cells lacking H2AX exhibit genomic instability and defects in the DDR pathway /Celeste et al. 2002, 2003; Bassing et al. 2003; Bogliolo et al. 2007; Chen et al. 2013). Thus, H2AX serves as a principal example for how histone modifications and variants play essential roles in attracting histone modification reader proteins to chromatin to facilitate DNA repair (Kouzarides 2007; Taverna et al. 2007). In addition to H2AX, recent reports have also shown that other $\mathrm{H} 2 \mathrm{~A}$ variants, including $\mathrm{H} 2 \mathrm{AZ}$ and macroH2A, are involved in regulating DNA repair (Xu et al. 2012a, b; Khurana et al. 2014). $\mathrm{MacroH} 2 \mathrm{~A}$ is recruited to DNA damage, where it compacts chromatin and promotes BRCA1 recruitment and
DSB repair by HR (Xu et al. 2012a; Khurana et al. 2014). Thus, $\mathrm{H} 2 \mathrm{~A}$ variants represent critical mediators of DSB repair within chromatin.

To identify novel chromatin-interacting DDR factors, we purified histone $\mathrm{H} 2 \mathrm{~A}$ variant complexes and identified their interacting proteins by mass spectrometry (MS). DNA damage localization and repair screens identified several new DNA damage factors, including ZMYM3 (zinc finger [ZNF], myeloproliferative, and mental retardation-type 3), a novel histone- and DNA-binding protein that uses these bivalent chromatin interactions to associate with DNA damage to facilitate the repair of DSBs. The recruitment of ZMYM3 requires the BRCA1-A complex, which together regulate BRCA1 localization on damaged chromatin to promote DNA repair by HR. Consistent with a role in HR repair, cells deficient for ZMYM3 exhibit genome instability, PARP inhibitor sensitivity, and an inability to survive in the presence of DSBs. Taken together, our data identified ZMYM3 as a new chromatin-interacting DDR factor that links the BRCA1-A complex to BRCA1 on chromatin, which acts to regulate the opposing activities of these factors to coordinate productive HR repair of DSBs.

\section{Results \\ Identification of ZMYM3 as a chromatin-interacting factor involved in DSB repair}

Histone $\mathrm{H} 2 \mathrm{~A}$ variants play a central role in orchestrating DDR activities within chromatin. Consistent with this notion, we observed a reduced ability of cells to perform DSB repair by HR in $\mathrm{H} 2 \mathrm{AX}$ - and macroH2A-depleted cells (Supplemental Fig. S1A, siRNA knockdown efficiency and cell cycle profiles shown in $\mathrm{B}, \mathrm{C})$, which is consistent with previous reports (Xie et al. 2004, 2007; Khurana et al. 2014). To better understand how HR repair occurs within chromatin, we sought to identify new chromatin-interacting factors that participate in the DDR. Given that histone $\mathrm{H} 2 \mathrm{~A}$ variants are key modulators of DNA repair and chromatin components, we performed tandem affinity purifications (TAPs) followed by MS for H2AX, H2AZ, and macroH2A histone $\mathrm{H} 2 \mathrm{~A}$ variants as a means to identify DDR factors that function within chromatin. From these data, we eliminated general contaminants as well as any protein identified in all three samples to remove general chromatin-bound proteins. We then compiled a list of the top 10 putative protein interactors for each $\mathrm{H} 2 \mathrm{~A}$ variant (Fig. 1A; Supplemental Fig. S1D; Supplemental Table 1). These results identified a number of known $\mathrm{H} 2 \mathrm{~A}$ variant-interacting proteins. For instance, MDC1 and 53BP1 were the top hits in our MS data for H2AX, which confirms the reported interactions between $\mathrm{H} 2 \mathrm{AX}$ and these DDR factors (Lee et al. 2005; Stucki et al. 2005; FradetTurcotte et al. 2013). In addition, analysis of these putative interacting proteins by Search Tool for the Retrieval of Interacting Genes/Proteins (STRING) database analysis (http://string.embl.de) revealed direct protein interaction networks for each of the three histone H2A variants (Supplemental Fig. S1E). Collectively, these results validated 

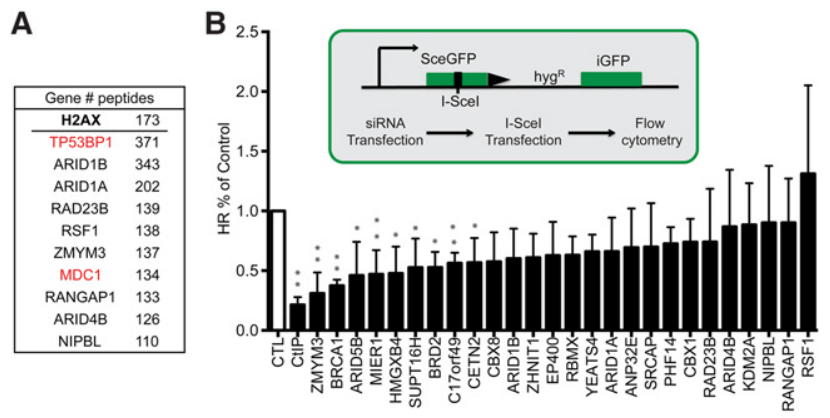

C

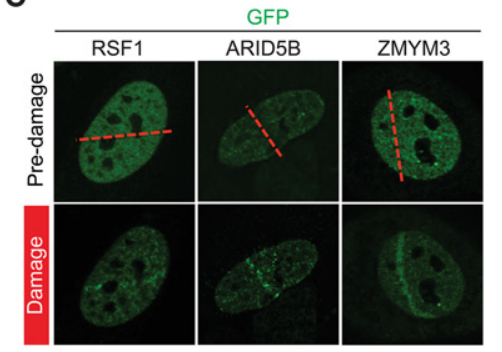

D

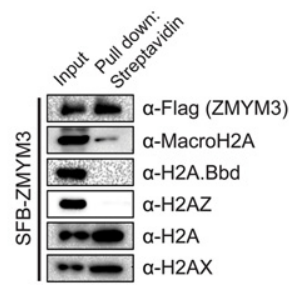

Figure 1. Identification of chromatin proteins involved in DNA DSB repair via HR. (A) Table of the top 10 proteins by peptide counts identified from histone H2AX variant TAP-MS samples. Proteins in red indicate known interactors. $(B)$ HR screen of putative H2A variant-interacting proteins from $A$ and Supplemental Figure S1D. HR efficiencies were obtained in cells transfected with siRNAs targeting all individual genes from $B$ and analyzed as in A. CtIP and BRCA1 acted as positive controls. Data represent mean \pm SD. $n=3$. (C) Recruitment of GFP-tagged proteins to laser damage. Cells expressing the indicated GFP-tagged proteins were damaged and analyzed 15 min after damage by confocal microscopy. Dotted red lines indicate the laser path. $(D)$ ZMYM3 interactions with H2A and its variants. Streptavidin pull-down of SFB-ZMYM3 was performed in HEK293T cells followed by Western blotting analysis. Flag detected SFB-ZMYM3, and endogenous core histone $\mathrm{H} 2 \mathrm{~A}$ and its variants were detected with specific antibodies. $\left({ }^{*}\right) P<0.05 ;\left(^{* *}\right) P<0.01$ versus the same treatment with control cells, Student's $t$-test.

our approach for identifying chromatin-interacting factors, including those previously reported to act through these histone $\mathrm{H} 2 \mathrm{~A}$ variants.

Considering that depletion of $\mathrm{H} 2 \mathrm{AX}$ or macroH2A resulted in deficient $\mathrm{HR}$, we performed a secondary screen of all putative chromatin-interacting proteins using the DR-GFP HR assay. From this screen, we detected a subset of genes that displayed defects in HR efficiency when depleted by siRNA (Fig. 1B; Supplemental Table 2). For candidates with the most prominent HR deficiencies, we analyzed the expression of the HR factor RAD51 to rule out siRNA off-target effects, which can occur following siRNA treatments (Supplemental Fig. S1F; Adamson et al. 2012). Since RAD51 levels were not reduced under these conditions, we next performed an additional assay on these positive hits to test their DNA damage recruitment, an ability shared by many DDR factors. We excluded well-studied DDR factors, including MDC1, 53BP1, and SRCAP, as well as several proteins that we were un- able to tag with GFP (e.g., ARID1A, ARID1B, EP400, and KDM2A). This analysis from 19 putative hits revealed that most proteins tested were not recruited to DNA damage (Supplemental Fig. S1G). However, in addition to the previously reported DDR protein RSF1 (Adamson et al. 2012; Helfricht et al. 2013), we identified two previously unreported proteins, ZMYM3 and ARID5B, which are recruited to DNA damage sites (Fig. 1C). From streptavidin pull-down assays, we detected a robust interaction between chromatin and stably expressed SFB-ZMYM3 (Fig. 1D). We did not detect any interaction between ZMYM3 and H2AZ or H2A.Bbd, suggesting that ZMYM3 may interact specifically with the histone $\mathrm{H} 2 \mathrm{~A} / \mathrm{H} 2 \mathrm{AX}$ and more modestly with macroH2A-containing chromatin (Fig. 1D). These results demonstrated that ZMYM3 is a chromatin-associated factor that promotes repair of DSBs by HR.

\section{ZMYM3 promotes genome stability}

Our initial characterization of ZMYM3 showing that it interacts with chromatin, is DNA damage-associated, and is required for efficient HR repair led us to focus our analysis on ZMYM3. ZMYM3 is reported to associate with a histone deacetylase complex and is found as a chromosomal translocation partner implicated in X-linked mental retardation (van der Maarel et al. 1996; Hakimi et al. 2003). Our results suggested that ZMYM3 is also involved in the DDR. Indeed, we observed rapid recruitment of GFP-tagged and endogenous ZMYM3 to $\gamma \mathrm{H} 2 \mathrm{AX}$-marked laser-induced DSB sites (Figs. 1C, 2A,B). To investigate further the involvement of ZMYM3 in the DDR, we generated ZMYM3 knockout cells in U2OS cells by CRISPR-Cas9 (Supplemental Fig. S2A,B). ZMYM3 knockout cells have normal cell cycle profiles compared with parental cells containing ZMYM3 (Supplemental Fig. S2C). In response to DNA damage, cells activate checkpoints to halt cell cycle progression and promote repair of the damaged DNA. ZMYM3 knockout cells failed to regulate the cell cycle checkpoints, as an increase in mitotic cells after DNA damage was observed in cells lacking ZMYM3 compared with control cells (Fig. 2C; Supplemental Fig. S2C). Consistent with the notion of ZMYM3 functioning in the DDR, ZMYM3 knockout cells exhibited persistent $\gamma \mathrm{H} 2 \mathrm{AX}$ signaling and a preponderance of chromosome breaks and aberrations in mitosis after DNA damage (Fig. 2D-F). To further investigate the involvement of ZMYM3 in DNA damage signaling, we treated ZMYM3 knockout cells with camptothecin (CPT), a TOP I inhibitor that results in DSBs in $S$ phase. In ZMYM3 knockout cells, we observed reduced Chk1 and RPA2 phosphorylation compared with wildtype cells after CPT treatment (Fig. 2G). Given that these signaling events are triggered by ssDNA production at DSBs, these results suggested that ZMYM3 might participate in DNA end resection. Taken together, our data demonstrated a requirement of ZMYM3 in maintaining genome integrity, which further highlighted its relevance in the DDR. 


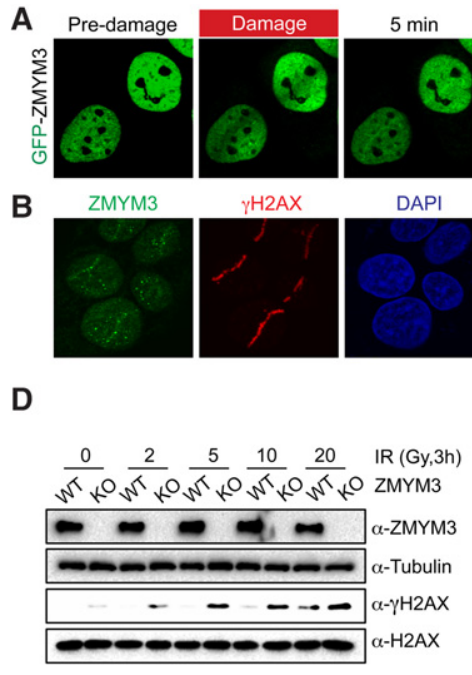

$\mathbf{F}$

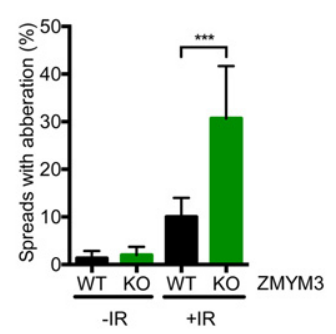

C

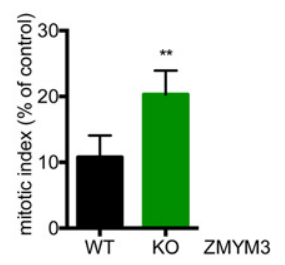

E

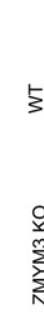

s $-I R$ 20 MERGE
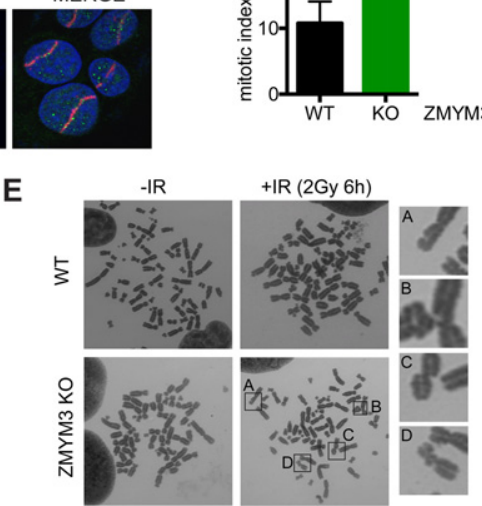

G

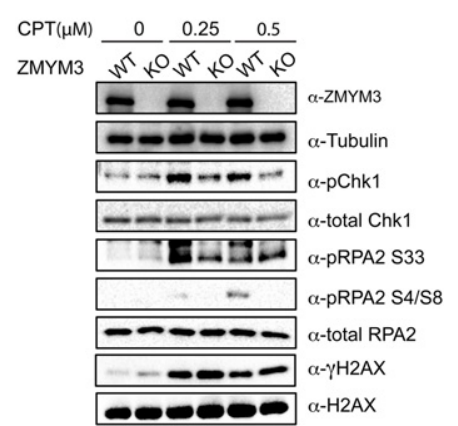

Figure 2. ZMYM3 localizes to DNA damage and promotes genome stability. (A) ZMYM3 localizes to DNA damage. Live imaging by confocal microscopy of GFPtagged ZMYM3 following laser-induced DNA damage. (B) Endogenous ZMYM3 accrual at DNA damage sites. Cells were damaged as in $A$ and analyzed by immunofluorescence $1 \mathrm{~h}$ after damage with anti-ZMYM3 antibodies. $\gamma \mathrm{H} 2 \mathrm{AX}$ marks DNA damage sites. $(C, D)$ ZMYM3 knockout cells exhibit defective checkpoint activation and signaling following DNA damage. Cells were damaged with IR followed by FACS analysis with anti-H3 pS10 and propidium iodide to identify mitotic cells. Data represent mean \pm SD. $n=3$. For $D$, cells were IRtreated with the indicated dose and analyzed by Western blotting with the indicated antibodies $3 \mathrm{~h}$ after IR. $(E, F)$ ZMYM3 knockout cells exhibit chromosome defects following DNA damage. Cells were either untreated or treated with IR and analyzed by metaphase spreads. Examples of chromosome aberrations are shown in $E$. Quantification of data from $E$ in $F$. Data were the average of three independent experiments. Mean \pm SD. $n=3 .(G)$ ZMYM3 knockout cells displayed DNA damage signaling defects following CPT treatment. Samples from CPT treatments were analyzed by Western blotting with the indicated antibodies $1 \mathrm{~h}$ after treatment. $\left.{ }^{* *}\right) P$ $\left.<0.01 ;{ }^{* * *}\right) P<0.001$ versus same treatment with control cells, Student's $t$-test.

\section{ZMYM3 recruitment is $\mathrm{H} 2 \mathrm{AX}$-dependent}

Since we observed an interaction between ZMYM3 and $\mathrm{H} 2 \mathrm{AX}$ and noted that DNA damage-related defects were similar in cells lacking either ZMYM3 or H2AX, we hypothesized that H2AX could directly regulate ZMYM3 damage recruitment. We first confirmed that ZMYM3 interacts with chromatin and that endogenous ZMYM3 is exclusively in the chromatin fraction (Fig. 3A; Supplemental Fig. S3A), although its chromatin association appeared to be DNA damage-independent (Fig. 3B). To better understand ZMYM3 interactions with chromatin, we generated a series of ZMYM3 deletion mutants according to its domain organization. ZMYM3 is a 1370-aminoacid protein containing 10 tandem ZNF domains along with a domain of unknown function, DUF3504 (Fig. 3C). $\mathrm{N}$-terminal deletion of ZMYM3 abolished its interaction with chromatin and $\mathrm{H} 2 \mathrm{~A} / \mathrm{H} 2 \mathrm{AX}$, while other deletions, including ZNF or DUF3504, did not alter this interaction (Fig. 3D). The $\mathrm{N}$-terminal 300 amino acids (i.e., $\mathrm{N}$-term) of ZMYM3 were sufficient for interactions with chromatin and $\mathrm{H} 2 \mathrm{~A} / \mathrm{H} 2 \mathrm{AX}$ (Fig. 3E). These results identify the region of ZMYM3 responsible for its interactions with chromatin. We next sought to test the functional importance of the ZMYM3 N terminus in the DDR. Deletion of this region greatly reduced ZMYM3 accumulation to DNA dam- age (Fig. 3F). These data suggested that chromatin binding via interactions with $\mathrm{H} 2 \mathrm{~A} / \mathrm{H} 2 \mathrm{AX}$ could facilitate ZMYM3 interactions with damaged chromatin. To further analyze the involvement of H2AX in ZMYM3 recruitment to DSBs, we generated U2OS cells devoid of H2AX (Supplemental Fig. S3B). Consistent with the identification of ZMYM3 as a chromatin-interacting protein, ZMYM3 recruitment to DNA damage was greatly reduced in H2AX knockout cells (Fig. 3G, quantified in H). These effects were specific to $\mathrm{H} 2 \mathrm{AX}$, as reconstitution of these cells with H2AX rescued ZMYM3 accumulation at damage sites. Reintroduction of H2AX-S139A, unlike wild-type H2AX, in H2AX knockout cells (Supplemental Fig. 3C) did not restore the ability of ZMYM3 to associate with damage sites, suggesting that DDR signaling as well as chromatin binding are required to promote ZMYM3 recruitment to damage sites (Fig. 3G, quantified in $\mathrm{H}$ ).

\section{ZMYM3 binds to dsDNA}

To evaluate any potential biological activity associated with ZMYM3, we performed a protein domain analysis using the protein homology/analogy recognition engine (Phyre2; http://www.sbg.bio.ic.ac.uk/phyre2). This analysis identified an evolutionarily conserved sequence within amino acids 300-330 of ZMYM3 that resembled a 
A

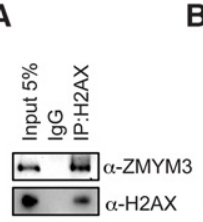

B

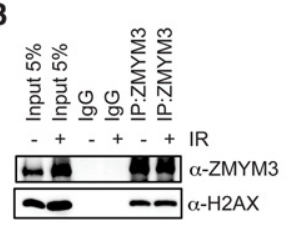

C

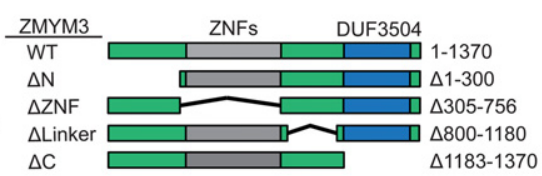

D

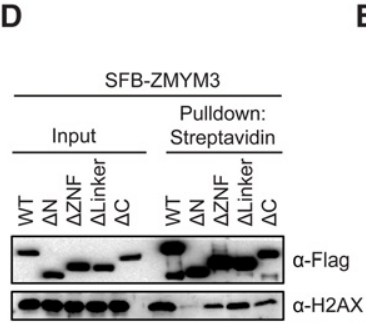

E

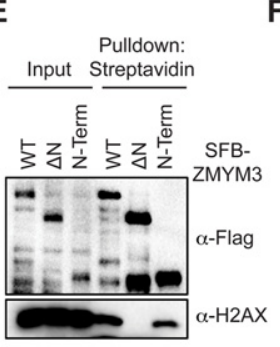

F
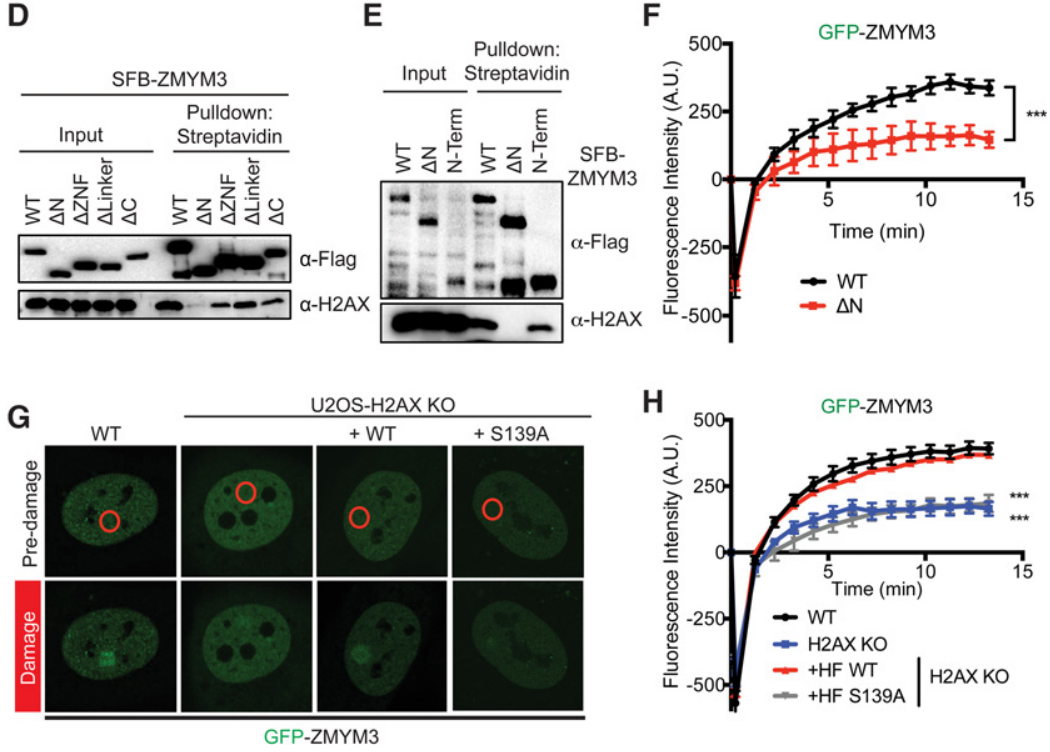

Figure 3. $\mathrm{H} 2 \mathrm{AX}$ is required for $\mathrm{ZMYM} 3$ recruitment to DSBs. $(A, B)$ Endogenous H2AX and ZMYM3 interact independently from DNA damage. Interactions of endogenous proteins were performed by immunoprecipitation and Western blotting, as indicated. IR treatment (10 Gy for 3 h). (C) Schematic diagram of ZMYM3 domain organization and deletion constructs. $(D, E)$ The $\mathrm{N}$ terminus of ZMYM3 is necessary and sufficient for chromatin binding. Interactions between H2AX and ZMYM3 were analyzed by streptavidin pull-down assays in HEK293T cells. Detection of endogenous $\mathrm{H} 2 \mathrm{AX}$ was performed by Western blotting. $(F)$ The $\mathrm{N}$ terminus of ZMYM3 is required for damage recruitment. Quantification of ZMYM3 and N-terminal deletion GFP-tagged protein recruitment to laser-induced DSBs were performed. Data represent mean \pm SEM. $n \geq 10$. $(G)$ H2AX promotes ZMYM3 accumulation at damage sites. Representative images of GFP-ZMYM3 laser-induced DSB recruitment in U2OS and H2AX knockout were analyzed. Note that expression of H2AX wild type, but not H2AX-S139A, rescues ZMYM3 recruitment to DNA damage in H2AX knockout cells. $(H)$ Quantification of $G$. Mean \pm SEM. $n \geq 6$. $\left(^{* * *}\right) P<0.001$ versus same treatment with control cells, Student's $t$-test. potential DNA-binding motif (Fig. 4A). To test whether ZMYM3 binds to DNA, we purified bacterially expressed MBP-tagged ZMYM3 N-terminal fragments (amino acids 1-300 and amino acids 1-330) and performed electromobility shift assays (EMSAs). The ZMYM3 amino acids 1-330, unlike the amino acids 1-300 fragment, readily bound dsDNA and, to a lesser extent, ssDNA (Fig. 4B; Supplemental Fig. S3D). These results mapped the dsDNA-binding capabilities of ZMYM3 to amino acids 300-330. ZMYM3 showed a high binding affinity toward dsDNA regardless of whether the target DNA was linear or circular, revealing a lack of binding preference toward DNA ends (Fig. 4B). We noted that the chromatinbinding region in ZMYM3 is adjacent to this DNA-binding domain (Fig. 4C). This region also showed binding to $\mathrm{H} 2 \mathrm{~A} / \mathrm{H} 2 \mathrm{AX}$ but not $\mathrm{H} 2 \mathrm{AZ}$ reconstituted nucleosomes (Fig. 4D; Supplemental Fig. S3E). Interestingly, ZMYM3 did not show binding to free histones (Supplemental Fig. $\mathrm{S} 3 \mathrm{~F})$. These results revealed that ZMYM3 interacts with $\mathrm{H} 2 \mathrm{~A} / \mathrm{H} 2 \mathrm{AX}$ in the context of the nucleosome.

We next investigated whether ZMYM3 chromatin- and/ or DNA-binding regions are required for its recruitment to DNA damage. Deletion of the DNA-binding domain ( $\triangle 300-330)$ of ZMYM3 reduced its ability to accumulate at DNA damage sites (Fig. 4E, quantified in F). Deletion of the ZMYM3 DNA-binding, chromatin, and H2A/ H2AX-interacting region $(\Delta 270-330)$ further reduced ZMYM3 recruitment to DNA damage sites. These data suggest that ZMYM3 uses both chromatin and DNA binding to achieve maximal associations with damaged chromatin (Fig. 4E,F).

\section{ZMYM3 interacts with the BRCA1-A subcomplex}

To gain further insights into the function of ZMYM3 in the context of the DDR, we performed a proteomic screen. From our MS results of tandem affinity-purified SFBtagged ZMYM3, we copurified several known ZMYM3interacting complexes, including NuRD, BHC, ZMYM2, and ZMYM4 (Fig. 5A; Hakimi et al. 2003). Consistent with our identification of ZMYM3 as a chromatin-interacting protein, we observed $\mathrm{H} 2 \mathrm{~A}, \mathrm{H} 2 \mathrm{AX}$, and macroH2A in our MS results for ZMYM3. We also identified RAP80 and BRE, which belong to the BRCA1-A DNA repair complex associated with ZMYM3 (Fig. 5A). These MS results were validated, as ZMYM3 interacted with RAP80, BRE, and ABRA1 in streptavidin pull-down experiments (Fig. 5B). Interactions between ZMYM3 and other members of the BRCA1-A complex, including MERIT40 and BRCC36, were not observed, suggesting that ZMYM3 associated specifically with a BRCA1-A subcomplex. To rule out overexpression effects, we confirmed these interactions with endogenous ZMYM3, RAP80, and ABRA1 (Fig. 5C). Nevertheless, these interactions were DNA damage-independent (Supplemental Fig. S4A).

We next sought to map these interactions within ZMYM3 and the BRCA1-A complex. Using deletion mutants of ZMYM3, we identified the C terminus of ZMYM3 as the interaction region for RAP80 and ABRA1, while the $\mathrm{N}$ terminus is required to interact with BRE (Fig. 5D,E; Supplemental Fig. S4B). The C terminus of ZMYM3 contains a DUF3504 domain, which is found in only six eukaryotic genes, including ZMYM2 
A

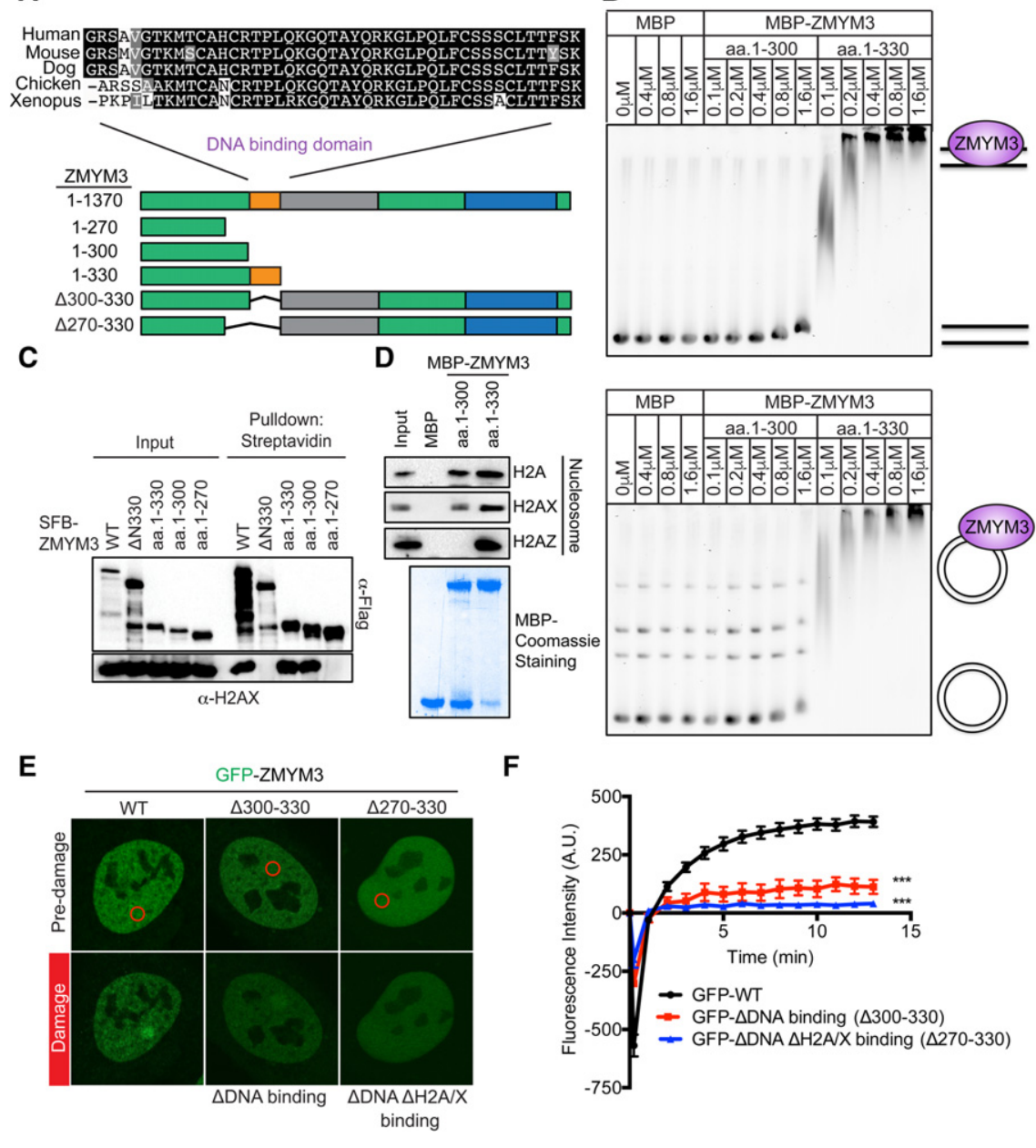

Figure 4. ZMYM3 binds histones and DNA to facilitate damage recruitment. $(A)$ The ZMYM3 DNA-binding domain and its conserved alignment across various species. Schematic diagram of the ZMYM3 domain structure; the deletion mutants used are indicated. $(B)$ ZMYM3 binds dsDNA independently from DNA ends. MBP-ZMYM3 fragments were expressed, purified, and analyzed by EMSA on dsDNA probes with (left panel) and without (right panel) DNA ends (see the Materials and Methods). (C) ZMYM3 interactions with chromatin and DNA occur through separate, independent domains. Streptavidin pull-down assay of SFB-ZMYM3 N-terminal fragments stably expressed in HEK293T were performed followed by Western blot analysis of endogenous H2AX. (D) ZMYM3 interacts with H2A- or $\mathrm{H} 2 \mathrm{AX}$-containing nucleosomes. In vitro reconstituted nucleosomes were incubated with MBP-ZMYM3 fragments followed by Western blot analysis. $(E, F)$ ZMYM3 chromatin and DNA-binding domains contribute to DNA damage interactions. Representative images of damage recruitment analysis of GFP-tagged ZMYM3 and derivative mutants in U2OS cells. Accumulation of ZMYM3 at damage sites from $E$ are quantified in $F .\left(^{* * *}\right) P<0.001$ versus same treatment with control cells, Student's $t$ test. and ZMYM4, which belong to the same family as ZMYM3 and share the same domain organization (Supplemental Fig. S4C; Kojima and Jurka 2011). Based on these findings, we tested whether ZMYM2 or ZMYM4 interacts with the BRCA1-A complex but did not observe any interaction with RAP80, suggesting unique ZMYM3 binding to this complex (Fig. 5F). Consistent with these results, the RAP80-binding region of ZMYM3 is not well conserved in ZMYM2 or ZMYM4 (Supplemental Fig. S4D). We identified a single nucleotide mutation, nucleotide $3821 \mathrm{G}>$ A p.R1274Q of ZMYM3, in COSMIC (Catalogue Of Somatic Mutations in Cancer), which falls within the RAP80 interaction domain within the highly evolutionarily conserved DUF3504 domain (Supplemental Fig. S4E). Recapitulation of this ZMYM3 mutation completely abolished its interaction with RAP80, which highlights the potential importance of this region in the DDR (Supplemental Fig. S4F). GFP-ZMYM3 R1274Q displayed increased cytoplasmic staining while still retaining its normal nuclear localization (Supplemental Fig. S4G). We observed that the damage recruitment of GFPZMYM3 R1274Q was greatly reduced (Supplemental Fig. S4G,H). We further mapped the ZMYM3-binding region of RAP80 to its ABRAl-interacting region (AIR), which was specifically required for ZMYM3 binding, while the Ub interaction motif (UIM) and ZNF regions were dispensable (Fig. 5G,H). These interactions appeared to be direct, as the purified bacterially expressed ZMYM3 $\mathrm{C}$ terminus interacted with the RAP80 AIR domain and ABRA1 as determined by in vitro protein interaction assays (Supplemental Fig. S4I). In addition to the $\Delta \mathrm{N}$ (Fig. $3 F), \Delta 300-330$ (DNA-binding domain), and $\Delta 270-330$ (chromatin-binding domain deletion) (Fig. 4E,F), other ZMYM3 deletion mutants also showed reduction in damage recruitment (Fig. 5I,J). Of these mutants, deletion of the $\mathrm{C}$ terminus exhibited the most severe defect in recruitment to the DNA damage site (Fig. 5I,J). Taken together, these data suggest that ZMYM3 contains several domains important for its DDR functions and that this protein interacts with the BRCA1-A subcomplex, including RAP80, ABRA1, and BRE (interactions summarized in Supplemental Fig. S4J).

\section{ZMYM3 regulates $\mathrm{ABRA} 1$ and $\mathrm{BRCA} 1$ recruitment to DSBS}

Since ZMYM3 binds several factors within the BRCA1-A complex, we considered that ZMYM3 participates in the 


\begin{tabular}{|c|c|}
\hline \multicolumn{2}{|c|}{$\mathbf{A}$} \\
\hline Gene \# & \# peptides \\
\hline ZMYM3 & 1311 \\
\hline CHD4 & 606 \\
\hline KDM1A & 526 \\
\hline RCOR1 & 255 \\
\hline HDAC2 2 & 191 \\
\hline RCOR3 & 185 \\
\hline HDAC1 & 174 \\
\hline ZMYM2 & 173 \\
\hline $\mathrm{H} 2 \mathrm{~A} / \mathrm{X}$ & 105 \\
\hline RCOR2 & 100 \\
\hline ZMYM4 & 67 \\
\hline UBB & 56 \\
\hline $\mathrm{MacroH} 2 \mathrm{~A}$ & 40 \\
\hline BRE & 7 \\
\hline RAP80 & 2 \\
\hline RAD18 & 2 \\
\hline
\end{tabular}

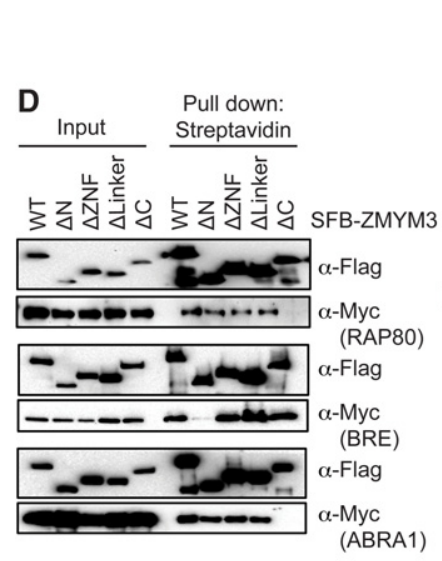

I

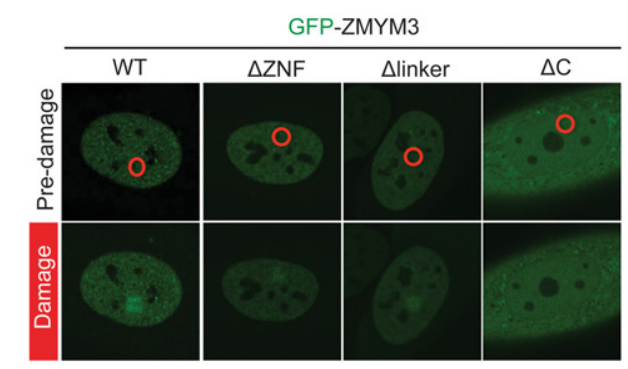

B

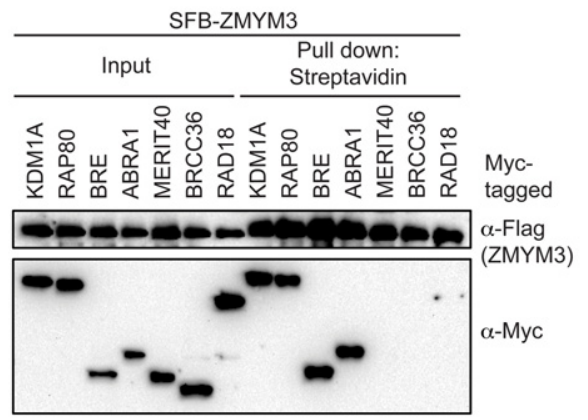

E

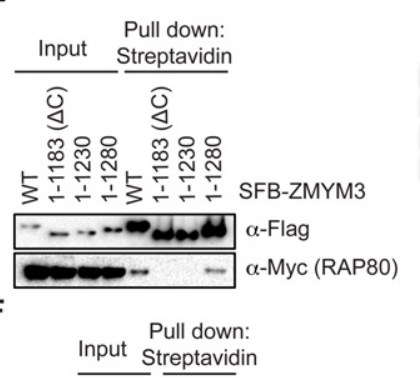

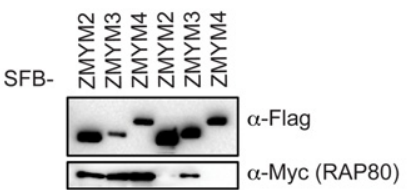

$\mathbf{J}$
C

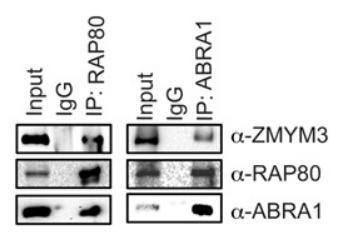

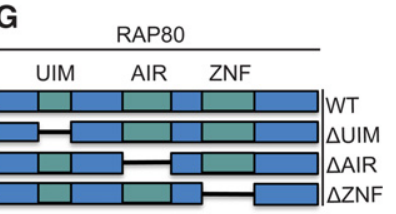
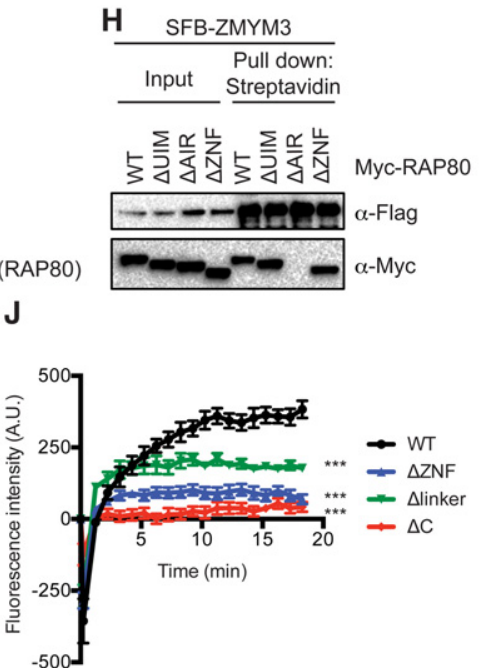

Figure 5. ZMYM3 interacts with components of the BRCA1-A complex. (A) TAP and MS analysis of ZMYM3. ZMYM3 was purified from HEK293T cells, and purified complexes were analyzed by MS. ZMYM3-associated proteins are listed. $(B)$ ZMYM3 interacts with BRCA1-A subcomplex members RAP80, ABRA1, and BRE. SFB-ZMYM3- and MYC-tagged protein was transiently expressed, purified with streptavidin, and analyzed by Western blotting. $(C)$ Endogenous ZMYM3 interacts with RAP80 and ABRA1. RAP80 and ABRA1 were immunoprecipitated from HEK293T cells using specific antibodies followed by Western blotting with anti-ZMYM3 to detect protein associations. (D) ZMYM3 interaction domain mapping with the BRCA1-A subcomplex. SFB-ZMYM3 and mutants were cotransfected with myc-tagged RAP80, ABRA1, or BRE. Complexes were purified with streptavidin pull-down, and interactions were analyzed by Western blotting. (E) Detailed domain mapping of ZMYM3-RAP80 interactions. Streptavidin pull-down of SFB-ZMYM3 and deletion mutants was performed in cells expressing Myc-RAP80. $(F)$ ZMYM3 specifically interacts with RAP80. Individual ZMYM proteins and RAP80 were cotransfected, and interactions were analyzed by streptavidin pull-down and Western blotting. (G) RAP80 domain structure and mutants. $(H)$ Identification of the RAP80 domain required for ZMYM3 binding. Streptavidin pull-down of SFB-ZMYM3 was performed in cells expressing Myc-RAP80 or deletion derivatives. Interactions were determined by Western blotting with Flag and Myc to identify ZMYM3 and RAP80, respectively. $(I, J)$ Damage recruitment of ZMYM3 mutants. GFP-tagged ZMYM3 wild type and variants were analyzed by laser damage in $I$ and quantified in $J$. Mean \pm SEM. $\left.n \geq 6 .{ }^{* * *}\right) P<0.001$ versus same treatment with control cells, Student's $t$-test.

DDR via these interactions. RAP80 is recruited to DNA damage and regulates the accumulation of BRCA1 and other BRCA1-A factors at damaged DNA (Kim et al. 2007a; Sobhian et al. 2007; Wang et al. 2007). We did not observe a significant difference in the ability of RAP80 to form IRIFs in ZMYM3 knockout cells (Fig. 6A; Supplemental Fig. S5A). In contrast, ABRA1 accumulation at damage sites was reduced in ZMYM3 knockout cells and abolished in both RAP80 and H2AX knockout cells (Fig. 6B; Supplemental Fig. S5B, knockout of RAP80 
A
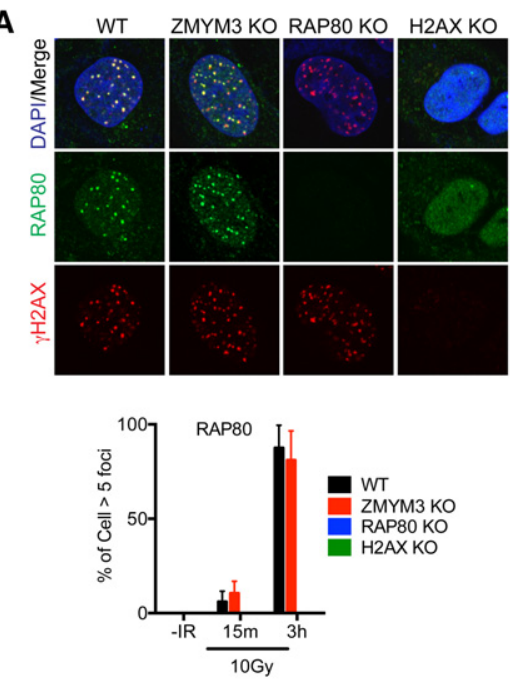

B
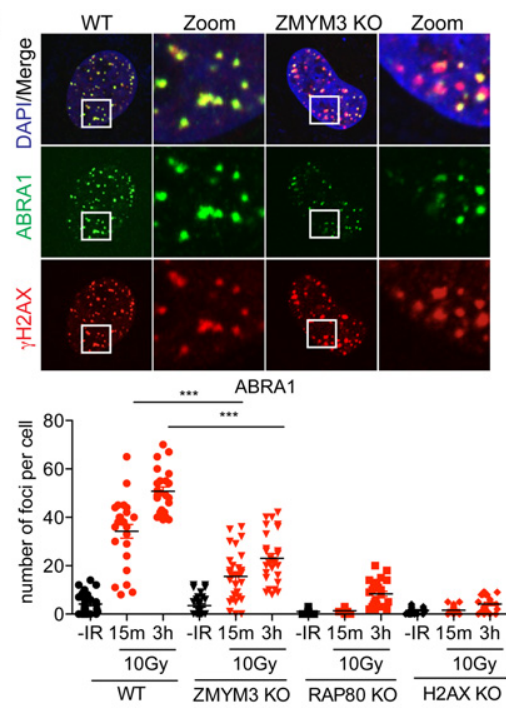

C
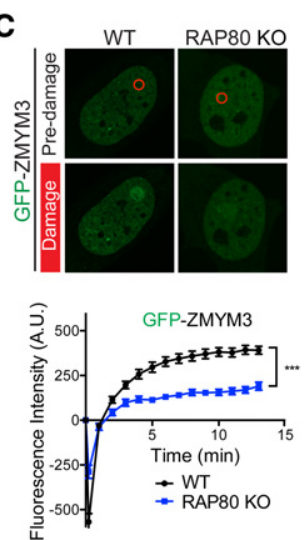

D

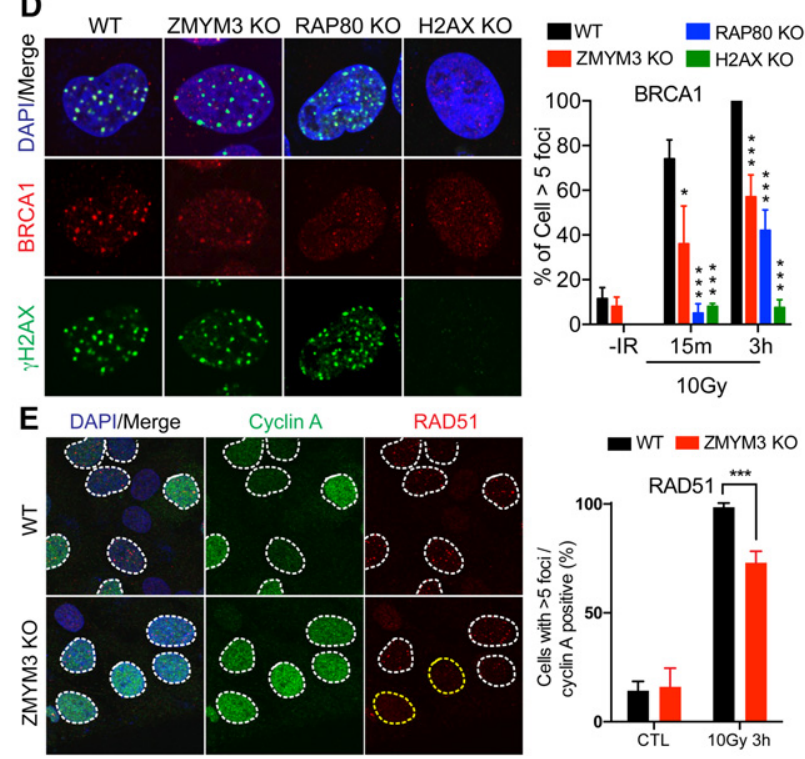

Figure 6. ZMYM3 promotes the recruitment of BRCA1 and its associated factor, ABRA1, to DSBs. (A) Analysis of endogenous RAP80 and $\gamma \mathrm{H} 2 \mathrm{AX}$ focus formation after $10 \mathrm{~Gy}$ of IR treatment for $3 \mathrm{~h}$ by immunofluorescence was performed in U2OS cells. Focus formation of RAP80 and $\gamma \mathrm{H} 2 \mathrm{AX}$ was analyzed in wild-type U2OS and compared with cells deleted for ZMYM3, RAP80, or H2AX. (Top panel) RAP80 foci after IR at the indicated time points were quantified from experiments performed in $A$ (bottom panel). (B) ABRA1 and $\gamma \mathrm{H} 2 \mathrm{AX}$ damage-induced foci were analyzed as in A. (Bottom panel) Quantification of the total number of ABRA1 foci per cell in the indicated cell background after IR treatment. (C, bottom panel) U2OS and RAP80 knockout cells stably expressing GFP-ZMYM3 were subjected to laserinduced irradiation and quantified. (D) BRCA1 focus formation was analyzed by immunofluorescence after IR treatment. Experiments were performed as in A. (Right panel) Quantification of BRCAl IRIFs as the percentage of cells with more than five foci. All quantification data are presented as mean \pm SD. $n=2$. (E) Analysis of RAD51 foci following IR by immunofluorescence. Parental and ZMYM3 knockout U2OS cells were costained with cyclin A, and RAD51 foci were quantified only in cyclin A-positive cells. $\left({ }^{*}\right) P<0.05$; $\left({ }^{* * *}\right) P<$ 0.001 versus same treatment in control cells, Student's $t$-test. confirmed in C) (Kim et al. 2007b; Liu et al. 2007). Although we observed that ABRAl still forms some $\gamma \mathrm{H} 2 \mathrm{AX}$-positive IRIFs in ZMYM3 knockout cells, the total number of foci per cell was greatly decreased compared with wild-type cells (Fig. 6B). For ZMYM3, its damage recruitment was reduced in RAP80 knockout cells (Fig. 6C), suggesting that RAP80 may influence ZMYM3 accumulation at DNA damage sites. Since ABRA1 is required for BRCA1 DSB recruitment through the BRCA1 BRCT domain (Kim et al. 2007b; Liu et al. 2007), we examined endogenous BRCA1 IRIFs and laser-induced damage recruitment of GFP-BRCT. We observed that BRCA1 accrual at damage sites is severely compromised in ZMYM3, RAP80, and H2AX knockout cells and that GFP-BRCT recruitment is defective in ZMYM3 knockout cells (Fig. 6D; Supplemental Fig. S5D). A previous study had reported that MERIT40 deficiency results in reduced BRCA1-A complex levels (Shao et al. 2009). To determine whether ZMYM3 could regulate BRCA1 and ABRA1 recruitment through protein stability of the complex, we analyzed protein levels of BRCA1-A complex members in wild-type and ZMYM3 knockout cells. Protein levels of individual components of the BRCA1-A complex were unaffected in ZMYM3 knockout cells, suggesting that the defects of ABRA1 and BRCA1 accumulation at damage sites upon ZMYM3 loss are not due to a reduction in protein levels of the BRCA1-A complex (Supplemental Fig. S5E). In addition, ZMYM3 loss did not affect the interaction between RAP80 and ABRA1-BRCA1 (Supplemental Fig. S5F). The effect of ZMYM3 on the BRCA1-A complex appeared to be specific and not a general DDR defect, as other RNF168 downstream repair proteins, including 53BP1 and RAD18, displayed normal DSB accrual in ZMYM3 knockout cells (Supplemental Fig. S5G,H). Collectively, our genetic and biochemical analyses indicate that ZMYM3 functions together with RAP80 and ABRA1 to transduce a requisite signaling event to regulate the accumulation of ABRA1 and BRCA1 at DSBs. 
A

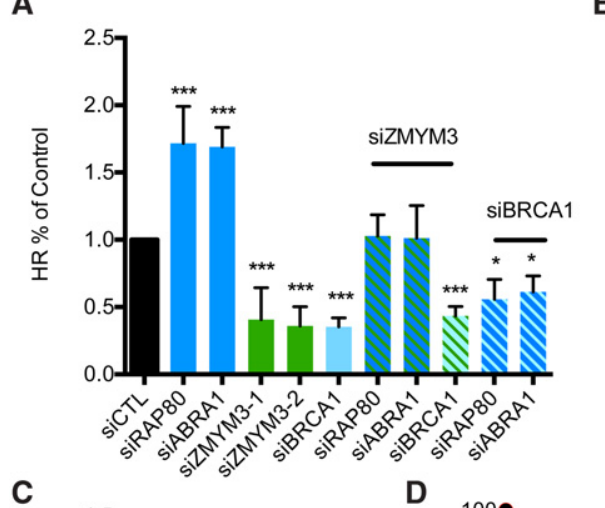

C

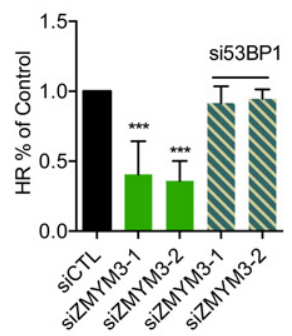

E

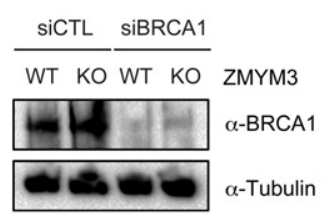

G

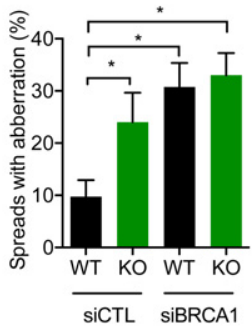

B

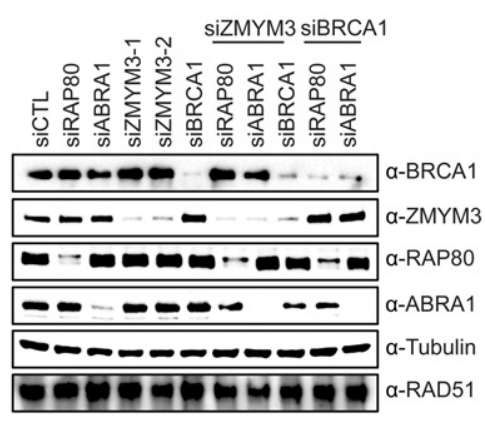

Figure 7. ZMYM3 antagonizes the BRCA1-A complex to promote HR. (A) ZMYM3 promotes HR and opposes RAP80 and ABRA1 inhibition of HR. DRGFP reporter assays were performed after depletion or codepletion of the indicated proteins by siRNAs. Data represent mean \pm SD. $n=3$. (B) Confirmation of knockdown efficiency by Western blotting from experiments performed in $A$. (C) 53BP1 depletion rescues HR defects in ZMYM3-depleted cells. Experiments were performed as in $A$. (D) ZMYM3 knockout cells are sensitive to IR and PARP inhibitors compared with parental U2OS cells. Cells were challenged with IR or PARP inhibitor as indicated and were analyzed by colony formation assays. Data represent mean \pm SD. $n=3$. (E) Western blotting analysis of knockdown efficiency in cells transfected with BRCA1 siRNA. $(F)$ Epistasis analysis of ZMYM3 and BRCA1. Wild-type and ZMYM3 knockout cells either alone or in combination with siBRCA1 were challenged with IR and PARP inhibitor followed by colony formation assays. $(G)$ Chromosome aberration analyses in ZMYM3 knockout and BRCA1 knockdown cells. Experiments were performed as in Figure 2E. $(H)$ Complementation assay of ZMYM3 knockout cells. ZMYM3 knockout cells with empty vector or wild-type ZMYM3 were analyzed as in D. $\left(^{*}\right) P<0.05 ;\left({ }^{* *}\right) P<0.01 ;\left({ }^{* * *}\right) P<0.001$ versus same treatment with control cells, Student's $t$-test.

ZMYM3 regulates HR repair via the BRCA1-A complex

Our primary screen identified ZMYM3 as a regulator of HR. In support of these findings, we observed a reduction of RAD51 at site-specific FokI endonuclease-generated DSBs and IRIFs (Supplemental Fig. S6A, quantified in B, E). Note that, for RAD51 IRIF analysis, we performed costaining with the S/G2 Cyclin A marker to ensure that our analysis took into account only those cells where HR occurs. Taken together, these data are consistent with ZMYM3 being involved in HR repair of DSBs. As reported previously, we also observed that depletion of RAP80 or ABRA1 increased HR repair (Fig. 7A,B; Coleman and Greenberg 2011; Hu et al. 2011b). While depletion of ZMYM3 reduced HR similarly to knockdown of BRCA1, codepletion of ZMYM3 with RAP80 or ABRA1, unlike BRCA1, resulted in wild-type levels of HR repair (Fig. 7A,B). Consistent with these results, we also observed that depletion of RAP80 in ZMYM3 knockout cells rescued RAD51 focus formation and DNA damage signaling following CPT treatment (Supplemental Fig. S6B,E). These data support the notion that ZMYM3 and RAP80 antagonize each other in the context of regulating HR, potentially through DNA end resection (Fig. 7A). Codepletion of ZMYM3 and BRCA1 resulted in HR deficiencies similar to single knockdown of either gene, which supported the involvement of ZMYM3 in this pathway (Fig. 7A,B). We also ensured that the siRNAs did not deplete RAD51 nonspecifically or affect cell cycle progression, thus ruling out these potential off-target effects (Fig. 7B; Supplemental Fig. S6C). Collectively, these data suggest that the BRCA1-A complex and ZMYM3 regulate BRCA1 jointly to ensure that the requisite levels of HR activities are engaged at DSBs for their repair.

HR defects occurring in BRCA1-deficient cells result in part from the inhibition of end resection by 53BP1 (Bunting et al. 2010). We observed that, similar to an ability of 53BP1 depletion to rescue BRCA1 HR deficiency, 
depletion of 53BP1 restored HR efficiency in ZMYM3deficient cells (Fig. 7C). Consistent with defects in HR repair, ZMYM3 knockout cells also display hypersensitivity to DNA damage by IR and PARP inhibitor, which are phenotypes that are well established to occur in BRCA1deficient cells (Fig. 7D). Knockdown of ZMYM3 did not affect NHEJ, suggesting that its role in DSB repair occurs primarily through HR (Supplemental Fig. S6D). Interestingly, while knockdown of BRCAl severely sensitized cells to X-ray and olaparib, while also showing increased chromosome aberration, these phenotypes were not increased in ZMYM3 knockout cells, suggesting that ZMYM3 and BRCA1 act in the same pathway (Fig. 7E-G).

We next attempted to investigate whether the chromatin-binding, DNA-binding, and BRCA1-A complex-binding regions of ZMYM3 that we identified were required for its recruitment and/or DDR functions. To this end, we stably re-expressed ZMYM3 wild-type and mutants in ZMYM3 knockout cells (Supplemental Fig. S7A,B). In these complementation assays, wild-type and, to a lesser extent, $\Delta$ linker, but not the other various mutants, were able to rescue IR and olaparib sensitivity, BRCA1 focus formation, and checkpoint defects as well as chromosome aberrations (Fig. 7H; Supplemental Fig. S7C-I). These results confirm that these phenotypes observed in ZMYM3 knockout cells were specific to ZMYM3. In addition, they also suggest that $Z M Y M 3$ requires multivalent interactions with DNA damage sites, including with chromatin, DNA, and the BRCA1-A complex, to fully promote its DDR functions. Taken together, our work identified ZMYM3 as a new BRCA1-A complex-interacting factor that facilitates BRCA1 accumulation within damaged chromatin to promote HR repair of DSBs (Supplemental Fig. S7J).

\section{Discussion}

In this study, we performed a proteomic and DNA repair screen to identify chromatin-associated proteins that promote repair of DSBs by HR. Our results identified ZMYM3, a new interactor and mediator of the BRCA1A complex. We determined that ZMYM3 is a bivalent chromatin-interacting protein that binds both dsDNA and $\mathrm{H} 2 \mathrm{~A} / \mathrm{H} 2 \mathrm{AX}$ histone proteins within the nucleosome. ZMYM3 accumulates at DNA damage sites, promotes survival to DSB-inducing agents, and regulates DSB repair by HR. Depletion of the BRCA1-A complex members RAP80, ABRA1, and BRCC36 leads to hyperresection, increased HR efficiency (Coleman and Greenberg 2011; Hu et al. 2011b; Ng et al. 2016), and defective BRCA1 IRIF formation (Chen et al. 2006; Kim et al. 2007b; Liu et al. 2007; Feng et al. 2009; Shao et al. 2009; Wang et al. 2009; Hu et al. 2011a). The loss of ZMYM3 also reduces BRCA1 IRIFs but, unlike other BRCA1-A complex members, reduces HR repair. Our observation that ZMYM3 directly binds to the BRCA1-A complex members RAP80, ABRA1, and BRE and is required for ABRA1 and BRCA1 damage recruitment suggests that ZMYM3 mediates the function of this complex at DNA damage sites on chromatin to facilitate DNA repair by HR (Supplemental Fig. S7J).
DNA damage signaling often necessitates the integration of both positive and negative inputs to modulate DDR activities to deliver the appropriate response. This concept is exemplified by the BRCA1-A complex, which restrains the HR-promoting activities of BRCA1 for HR repair. While deficiencies of RAP80, ABRA1, or BRCC36 increase $\mathrm{HR}$, these conditions also decrease the accumulation of the HR-promoting factor BRCA1. These somewhat counterintuitive results have led to the proposal that the BRCA1-A complex acts to restrain DNA end resection and DNA repair activities (Coleman and Greenberg 2011; Hu et al. 2011b). Deletion of ZMYM3, on the other hand, results in decreased HR, a phenotype observed only by the deficiencies of BRCA1 within the BRCA1-A complex. As the HR inhibitory factors RAP80 and ABRA1 are recruited to DNA damage sites, it raises the question of how BRCA1 facilitates HR repair in the presence of these inhibitory BRCA1-A complex members. Our data are in line with the idea that ZMYM3 acts to harness the HR-suppressive properties of the BRCA1-A complex. ZMYM3 directly binds RAP80 and ABRA1, which could represent the physical interactions that link ZMYM3 to the BRCA1-A complex. ZMYM3 also facilitates BRCA1 accumulation at DSBs, which ensures its requisite loading for HR repair. In support of this model, depletion of ZMYM3 as well as BRCA1 reduces the excessive $\mathrm{HR}$ observed in RAP80- and ABRA1-depleted cells (Fig. 7A; Supplemental Fig. S6B). Conversely, loss of ZMYM3, BRCA1, or both factors results in defects in HR efficiencies, IR and PARP inhibitor sensitivities, and chromosomal aberrations (Fig. 7). While BRCA1-deficient cells exhibit more severe DDR defects than ZMYM3 knockout cells, loss of both of these factors does not further exacerbate their DDR defects when compared with those observed in BRCA1-depleted cells (Fig. 7F,G). Like BRCA1 deficiency, depletion of 53BP1 restores HR levels in ZMYM3-depleted cells (Fig. 7C; Bunting et al. 2010). These findings provide additional evidence that ZMYM3 functions within the BRCA1 pathway to promote DDR activities, including HR repair.

Lys63-linked Ub chains (K63-Ub) are induced at damage sites, which are bound by the UIMs of RAP80 to facilitate the initial recruitment of the BRCA1-A complex to damaged chromatin (Kim et al. 2007a; Sobhian et al. 2007; Wang et al. 2007). In addition to K63-Ub, our data revealed ZMYM3 as an additional mediator of BRCA1-A complex accumulation at damage sites. ZMYM3 binds chromatin and is recruited to DNA damage sites. Deletion mapping identified an $\mathrm{H} 2 \mathrm{~A} / \mathrm{H} 2 \mathrm{AX}-$ binding region and a DNA-binding domain in the $\mathrm{N}$ terminus of ZMYM3 (Fig. 4B,D; Supplemental Fig. S3D). These two domains are required for maximal interactions between ZMYM3 and DNA damage sites (Fig. 4E,F), suggesting that they could act to stabilize ZMYM3 and the BRCA1-A complex on damaged chromatin. RAP80 contains both Ub- and histone-binding capabilities. Indeed, the two CCHC ZNF domains of RAP80 have been shown to bind histone H2B (Wu et al. 2012). It is worth investigating whether this region of RAP80 also binds DNA, a function previously ascribed to these types of ZNFs. These multivalent interactions 
between RAP80, Ub, and chromatin could explain the ability of RAP80 to bind DNA damage sites in the absence of ZMYM3 (Fig. 6A). In addition to chromatin binding, ZMYM3 required $\mathrm{H} 2 \mathrm{AX}$ phosphorylation (i.e., $\gamma \mathrm{H} 2 \mathrm{AX}$ ) for its accumulation at DNA breaks (Fig. 3H; Kim et al. 2007a; Sobhian et al. 2007). Deletion of the ZMYM3 Cterminal DUF3504 domain, which is responsible for RAP80-ABRA1 interaction, greatly reduced its DSB accumulation. In addition, given that ZMYM3 recruitment is partially RAP80-dependent, the requirement of $\gamma \mathrm{H} 2 \mathrm{AX}$ for ZMYM3 recruitment is likely explained by the inability to recruit RAP80 in H2AX- and MDC1-deficient cells (Fig. 6C; Kim et al. 2007a; Sobhian et al. 2007). Taken together, the identification of ZMYM3 as a chromatin-binding factor that interacts with the BRCA1-A complex reveals mechanistic insights into how this multiprotein complex accumulates on chromatin at DNA damage sites to facilitate DDR activities required for HR repair and genome stability.

In addition to the well-established tumor suppression functions of BRCA1 and the prevalence of its deficiency in breast and ovarian cancer, other members of the BRCA1-A complex have also been implicated in cancer. For example, mutations in RAP80 have been identified in familial breast and ovarian cancers (Nikkila et al. 2009; Bian et al. 2012), and RAP80 ${ }^{-/}$mice are prone to tumorigenesis (Wu et al. 2012). Interestingly, several metaanalyses reported ZMYM3 as highly mutated in different types of cancer, including chronic lymphocytic leukemia (Wang et al. 2011; Puente et al. 2015; Amin et al. 2016), medulloblastoma (Robinson et al. 2012), Ewing sarcoma (Tirode et al. 2014), and pediatric cancer (Huether et al. 2014). Most ZMYM3 mutations identified in cancer genomes are predicted to be loss-of-function mutations (COSMIC) (Huether et al. 2014). In support of the DDR function of ZMYM3 impacting tumorigenesis, we found that the ZMYM3 mutation identified in COSMIC (nucleotide $3821 \mathrm{G}>$ A p.R1274Q) disrupted its interaction with RAP80 (Supplemental Fig. S4F). Defects in DDR pathways represent attractive targets for cancer treatment, including by DNA-damaging agents and a number of other successful examples of pharmacological inhibition of target proteins, leading to synthetic lethality against DDR-deficient cancer cells (Curtin 2012). These include the use of PARP inhibitors to treat HR-deficient cancers such as those with mutations in BRCA1 and BRCA2. Given our data demonstrating the involvement of ZMYM3 in regulating BRCA1 and HR repair as well as its sensitivity to IR and PARP inhibitors, future studies are warranted to explore the therapeutic benefit of these treatments in cancers deficient for ZMYM3.

\section{Materials and methods}

\section{Cell culture, transfection, and retroviral infection}

HEK293T and U2OS cells were purchased from American Type Culture Collection and cultured in Dulbecco's modified Eagle's medium (DMEM) with 10\% fetal bovine serum supplemented with $100 \mathrm{U} / \mathrm{mL}$ penicillin and $100 \mu \mathrm{g} / \mathrm{mL}$ streptomycin at $37^{\circ} \mathrm{C}$ in the presence of $5 \%$ of $\mathrm{CO}_{2}$. U2OS FokI reporter cells were cultured in $100 \mu \mathrm{g} / \mathrm{mL}$ hygromycin B. Transfection of HEK293T and U2OS was carried out using Lipofectamine 2000 (Thermo Fisher Scientific) and Fugene (Promega), respectively, according to the manufacturer's instructions. For all reconstitution experiments, we used N-terminal HA-Flag-tagged retroviral infection. Viruses were generated using BOSC23 cells by transfection with packaging vector pCLampho. Viruses were harvested $48-96 \mathrm{~h}$ after transfection and used to infect cells together with polybrene. Cells were selected with puromycin and analyzed by Western blotting and immunofluorescence. The U2OS-DSB reporter cell line was used to quantify RAD51 recruitment to DSBs. Cells were treated with Shield-1 and 4-OHT for $3 \mathrm{~h}$ to induce site-specific DSBs (Tang et al. 2013).

\section{Plasmids and RNAi}

Human ZMYM3 was amplified by PCR from HEK293T cDNA. RAP80, ABRA1, BRE, and BRCC36 pDONR vectors were generously provided by Dr. Lin Feng (Sun Yat-sen University Cancer Center). The cDNAs were cloned into pDONR201 vector using gateway cloning (Invitrogen). All cDNAs were verified by sequencing and subcloned into pDEST (S-protein, Flag, and streptavidin binding; GFP; myc; MBP; GST; and HA-Flag) vectors using gateway LR reactions. Mutations were created using QuikChange site-directed mutagenesis kit (Agilent Genomics) according to the manufacturer's instructions. The library of siRNA pools used in screening was purchased from Dharmacon. Specific siRNA sequences were used for targeting RAP80 (5'-CCAGUUGGAGG UUUAUCAA-3'), ABRA1 (5'-ACACAAGACAAACGAUCUAU U-3'), BRCA1 (SiGenome SMARTpool M-003461-02-0005), CtIP (5'-GCUAAAACAGGAACGAAUC-3'), and 53BP1 (5'-GAGAG CAGAUGAUGAUCCUUUA- ${ }^{\prime}$ ). Nontargeting siRNA pools were used as controls. siRNA transfections were performed using Lipofectamine RNAiMax (Invitrogen) according to the manufacturer's instructions.

\section{Antibodies}

Primary antibodies used in this study were Flag M2 (Sigma, F1804), Myc (Santa Cruz Biotechnology, SC-40), H2AX (Millipore, 07-627), $\gamma \mathrm{H} 2 \mathrm{AX}$ (Millipore, 05-636), H2AZ (Cell Signaling, 2718S), macroH2A (Abcam, AB37264), H2A.Bbd (Millipore, 06-1319), ZMYM3 (Abcam, AB106626), ATM (Santa Cruz Biotechnology, SC-135663), pATM S1981 (Abcam, AB81292), $\beta$-tubulin (Abcam, AB6046), RAD51 (Abcam, AB88572), RAP80 (Bethyl Laboratories, A300-763A), ABRA1 (Abcam, AB139191), BRCA1 (Santa Cruz Biotechnology, SC-6954), HRP-linked anti-GST (Sigma, A7340), MBP (Abcam, AB9084), phospho-H3 S10 (Cell Signaling, 3377), 53BP1 (Novus Biologicals, NB100-304), RAD18 (Cell Signaling, 9040), RPA2 (Abcam, AB2175), pRPA2 S33 (Bethyl Laboratories, A300-246), pRPA2 S4/S8 (Bethyl Laboratories, A300-245), Chk1 (Santa Cruz Biotechnology, SC-8408), and pChk1 (Cell Signaling, 2348). For Western blotting analysis, secondary antibodies HRPlinked anti-rabbit IgG and HRP-linked anti-mouse IgG were purchased from Cell Signaling. For immunofluorescence, Alexa fluor 488 goat anti-rabbit and Alexa fluor 594 goat anti-mouse were used (Invitrogen).

\section{Coimmunoprecipitation, pull-down, and Western blotting}

Cells were lysed in NETN buffer (150 mM NaCl, 0.5 mM EDTA, $20 \mathrm{mM}$ Tris- $\mathrm{HCl}$ at $\mathrm{pH} 7.5,0.5 \%$ NP-40) with protease inhibitors and TurboNuclease (Accelagen). For immunoprecipitation of endogenous proteins, cell lysates were incubated with protein-A 
beads and the indicated antibodies for $2 \mathrm{~h}$ at $4^{\circ} \mathrm{C}$. For precipitation of SFB-tagged proteins, cell lysates were incubated with streptavidin beads (GE Healthcare) for $2 \mathrm{~h}$ at $4^{\circ} \mathrm{C}$. For GST pull-down assays, full-length ABRA1 protein and fragments (RAP80-AIR: amino acids 227-346; ZMYM3 CT: amino acids 1000-1370) harboring N-terminal GST or MBP tags (pDEST-GST and pDEST-MBP) were expressed in the BL21 bacterial strain and immobilized and purified using glutathione sepharose (GE Healthcare) or amylose resin (GE Healthcare), respectively. MBP fusion proteins were eluted with $10 \mathrm{mM}$ maltose for GST pull-down assay. Immunocomplexes or pull-down complexes were washed with NETN buffer three times and eluted by boiling in $1 \times$ laemmli buffer. Samples were resolved by SDS-PAGE, transferred to nylon membranes, and immunoblotted with antibodies as indicated.

\section{HR and NHEJ assay}

U2OS cells containing DR-GFP reporter (U2OS-DR) or a NHEJ reporter (EJ-5) were transfected with the indicated siRNAs $24 \mathrm{~h}$ after seeding followed by transfection with I-SceI-expressing vector (pCAG-I-SceI) or control vector (pCAG) (Gunn et al. 2011). Cells were harvested $72 \mathrm{~h}$ after siRNA transfection and analyzed by flow cytometry for GFP-positive cells with a BD Accuri flow cytometer (BD biosciences). Data were normalized to control siRNA cells transfected with I-Sce1-expressing vector.

\section{Laser microirradiation}

Laser damage was created using a FluoView 1000 confocal microscope (Olympus) as described previously (Gong et al. 2015). Cells were seeded onto glass coverslips or glass-bottomed dishes (Willco Wells) and incubated with $10 \mu \mathrm{M}$ BrdU for $24 \mathrm{~h}$. For immunostaining, cells were subjected to laser-induced damage with a fixed-wavelength $405-\mathrm{nm}$ laser using a $60 \times$ objective at $60 \%$ power on an inverted FluoView 1000 confocal microscope (Olympus). For live-cell imaging for GFP recruitment studies, cells stably expressing GFP-tagged proteins were subjected to laser-induced damage, and live images were captured in 60-sec intervals. The fluorescence intensity of the GFP-tagged protein in the damaged region was normalized with an equivalent undamaged area in the same cell.

\section{Immunofluorescence and confocal microscopy}

Immunofluorescence was performed as described previously (Leung et al. 2014). Briefly, cells were cultured on poly-L-lysine coverslips (BD Biosciences) before analysis. Coverslips were washed in PBS and pre-extracted with CSK buffer for $10 \mathrm{~min}$ followed by fixing in $5 \%$ paraformaldehyde for $15 \mathrm{~min}$ at room temperature. Samples were incubated with the indicated primary antibodies overnight at $4^{\circ} \mathrm{C}$, washed, and incubated with secondary antibodies for $30 \mathrm{~min}$. Samples were then counterstained with DAPI and mounted onto glass slides with anti-fade solution $(0.02 \%$ p-phenylenediamine [Sigma, P6001] in 90\% glycerol in PBS). Samples were visualized using an inverted FluoView 1000 confocal microscope (Olympus). Z-stacked images were obtained for images and focus counting, which was performed with FluoView 3.1 software. Data were analyzed using GraphPad Prism 6.0. To quantify the recruitment of RAD51 to the FokI-mediated site-specific DSBs upon ZMYM3 knockdown, we used a DSBs reporter cell line as described previously (Tang et al. 2013). DSBs were induced by incubating with shield-1 and 4-OHT for 3 h. Cells were then stained with RAD51 antibody and analyzed with immunofluorescence using confocal microscopy.

\section{EMSA}

MBP-fused ZMYM3 N-terminal fragments were expressed in BL21 bacteria, purified, and eluted from amylose resin. EMSAs in the Figure 4B were performed using unlabeled DNA substrate (circular DNA and restriction enzyme linearized DNA). DNA substrates were incubated with MBP-ZMYM3 for $30 \mathrm{~min}$ on ice and resolved on a $1 \%$ agarose gel using $0.5 \times$ TBE running buffer, stained with SYBR Green, and visualized in Chemidoc (BioRad). EMSAs in Supplemental Figure S3C were performed as described previously (Makharashvili et al. 2014). Briefly, $\left[{ }^{32}\right.$ Pcordycepin]-labeled oligonucleotides TP2622 (ssDNA) or TP2622 annealed to TP124 (dsDNA) were used as DNA substrates. DNA substrates $(0.125 \mathrm{nM})$ were incubated with MBP-ZMYM3 fragments in DNA-binding buffer for $30 \mathrm{~min}$ on ice and resolved in native acrylamide gels with $0.5 \times$ TBE running buffer. Gels were dried, exposed to phosphoscreen, and analyzed with a phosphorimager (GE).

\section{Colony formation survival assays}

Cells were seeded at a density of 750 cells per well in a six-well plate in triplicate. Cells were treated with IR or olaparib as indicated $24 \mathrm{~h}$ after seeding. After 10-14 d, cells were fixed and stained with $0.5 \%$ crystal violet in $20 \%$ ethanol followed by manual counting of visible colonies.

\section{Metaphase spread and chromosome aberration analysis}

Metaphase spreads were performed as described previously with minor modifications (Leung et al. 2012). Cells were plated in 6$\mathrm{mm}$ dishes for $24 \mathrm{~h}$. After seeding, cells were irradiated with 2 Gy (Faxitron X-ray system, RX650) followed by incubation with colcemid for $6 \mathrm{~h}$. Samples were swollen with hypotonic solution $(0.075 \mathrm{M} \mathrm{KCl} / \mathrm{PBS})$ for $10 \mathrm{~min}$ at room temperature and then fixed with 3:1 methanol:acetic acid overnight at $4^{\circ} \mathrm{C}$. Suspensions of cells in 3:1 methanol:acetic acid were dropped onto slides and allowed to dry. Slides were stained with Giemsa, and 50 metaphase spreads were scored for chromosome breaks in two independent experiments.

\section{TAP and liquid chromatography-tandem MS (LC-MS/MS)}

H2A variants and ZMYM3 were cloned into $\mathrm{N}$-terminal-tagged SFB (S-protein, Flag, and streptavidin-binding protein) vectors and stably expressed in HEK293T. For ZMYM3, cells were harvested with NETN buffer with Turbo-Nuclease for $1 \mathrm{~h}$ at $4^{\circ} \mathrm{C}$. For H2A variant purification, cells were extracted with NETN for $20 \mathrm{~min}$ at $4^{\circ} \mathrm{C}$. The pellets were then digested with Turbo-Nuclease for $1 \mathrm{~h}$ at $4^{\circ} \mathrm{C}$ and collected as the chromatin fraction. The chromatin fraction was incubated with streptavidin beads for $1 \mathrm{~h}$ followed by washing with NETN buffer three times and eluted with $2 \mathrm{mM}$ biotin at $4^{\circ} \mathrm{C}$. The eluent was then incubated with $\mathrm{S}$-protein beads overnight at $4^{\circ} \mathrm{C}$. The immunocomplexes were then washed and eluted with SDS-PAGE sample buffer. Samples were subjected to SDS-PAGE, stained, excised, and stored at $-20^{\circ}$ C before performing MS (Shevchenko et al. 2006).

LC-MS/MS analysis was performed with a Dionex Ultimate 3000 NSLC nano-HPLC interfaced to a Velos Pro mass spectrometer (Thermo Scientific Instruments). Approximately $2 \mu \mathrm{g}$ of the in-gel protein digest was injected and preconcentrated using a 100- $\mu \mathrm{m}$ ID trap column (New Objective IntegraFrit) packed to 5 cm with $5 \mu \mathrm{m}$ Michrom Magic C18 AQ. Preconcentration occurred for $10 \mathrm{~min}$ using $2 \%$ acetonitrile/ $0.1 \%$ formic acid at a flow rate of $5 \mu \mathrm{L} / \mathrm{min}$. The column was then switched in-line 
with a 75 - $\mu \mathrm{m} \mathrm{ID} \times 15$-cm-long analytical column (New Objective PicoFrit) packed with $3.5 \mu \mathrm{m}$ of Waters Xbridge C18 resin. Separation was performed with mobile phase A consisting of $0.1 \%$ formic acid in water, and mobile phase B consisting of $0.1 \%$ formic acid in acetonitrile was applied as a 150-min linear gradient from $2 \%$ to $45 \%$ eluent $\mathrm{B}$ at a flow rate of $300 \mathrm{~nL} / \mathrm{min}$. MS/MS analysis was performed using a normalized collision energy of $35 \%$ on the top 10 most abundant precursor ions. Proteome Discoverer Sequest was used for proteomic analysis of the immunoprecipitated samples. The resulting LC-MS/MS runs were searched against the reviewed human database from Universal Protein Resource (UniProt) with the following settings. The peptide mass tolerance was set to $\pm 1.20 \mathrm{Da}$ with a fragment ion tolerance of \pm $0.8 \mathrm{Da}$. The peptide length was constrained by a minimum length of five amino acids. Three missed cleavages were allowed for trypsin. Peptides were filtered against a $1 \%$ false discovery rate for positive identification, and protein identifications were confirmed by at least two unique peptides. UniProt accession numbers were then used for further analysis.

\section{Genome editing with CRISPR-Cas9}

CRISPR-Cas9 technology was used to generate gene knockout cell lines in U2OS cells. Two individual guide RNAs (gRNAs) were designed for H2AX (5'-GGTGGCCTTCTTGCCGCCCG$3^{\prime}$ and $5^{\prime}$-CGCCAACGCGCTCGGCGTAG- $\left.3^{\prime}\right)$, ZMYM3 (5'-GG TACAGGTCTTTTTGCCCG- ${ }^{\prime}$ and 5'-AGGCAGCCCCTTGC GCTGAT- $\left.3^{\prime}\right)$, and RAP80 (5'-ATTGTGATATCCGATAGTG AT- $3^{\prime}$ and $5^{\prime}$-GTTCTGTCAGTGTGAAGAGG- $3^{\prime}$ ) and cloned into pSpCas9(BB)-2A-Puro (PX459, a gift from Feng Zhang [Addgene plasmid no. 48139]), and genome editing was performed similarly to that previously published (Ran et al. 2013). Briefly, cells were transfected with mammalian expression vectors containing gRNAs using Fugene according to the manufacturer's instructions. The cells were then allowed to recover for $2 \mathrm{~d}$ and diluted into 96-well plates. Single colonies were isolated after 2-3 wk, expanded, and screened by Western blotting and immunofluorescence analyses to detect gene knockouts.

\section{Mitotic index and cell cycle}

Cells were treated with IR with the indicated dose and harvested at each given time point. Cells were trypsinized and fixed in $80 \%$ ethanol overnight at $4^{\circ} \mathrm{C}$. For mitotic index, cells were stained with H3 S10-P for $2 \mathrm{~h}$ followed by Alexa fluor 488 for $1 \mathrm{~h}$ at room temperature. Cell cycle was analyzed by staining with 4 $\mu \mathrm{g} / \mathrm{mL}$ propidium iodide followed by treatment with $2 \mu \mathrm{g} / \mathrm{mL}$ RNase for $30 \mathrm{~min}$ at room temperature. Cells were analyzed by flow cytometry, and data were processed with FlowJo software.

\section{Acknowledgments}

We thank all of our laboratory members and Blerta Xhemalce (University of Texas at Austin) for insightful comments. We also thank Dr. Lin Feng (Sun Yat-sen University Cancer Center) for the RAP80, ABRA1, BRE, MERIT40, and BRCC36 cDNAs, and Jeremy Stark (City of Hope) for the EJ5 NHEJ reporter cell line. Support for this project was provided by grants to D.D. (Canadian Institutes of Health Research [CIHR] FDN143343), J.S.B. (Welch Foundation F-1155 and National Science Foundation CHE1559839), and T.T.P. (Cancer Prevention Research Institute of Texas [CPRIT] RP110465). A.S. is supported by a CIHR doctoral scholarship. This work in the K.M.M. laboratory was supported in part through grants from CPRIT (R1116), National Institutes of Health (R01CA198279), and the American Cancer Society (RSG-16-042-01-DMC). J.W.C.L. was partially supported by a training grant from CPRIT (RP140108).

\section{References}

Adamson B, Smogorzewska A, Sigoillot FD, King RW, Elledge SJ. 2012. A genome-wide homologous recombination screen identifies the RNA-binding protein RBMX as a component of the DNA-damage response. Nat Cell Biol 14: 318-328.

Amin N, Seymour EK, Saiya-Cork K, Parkin B, Shedden K, Malek S. 2016. A Quantitative analysis of subclonal and clonal gene mutations pre- and post-therapy in chronic lymphocytic leukemia. Clin Cancer Res 22: 4525-4535.

Aplan PD. 2006. Causes of oncogenic chromosomal translocation. Trends Genet 22: 46-55.

Bassing CH, Suh H, Ferguson DO, Chua KF, Manis J, Eckersdorff M, Gleason M, Bronson R, Lee C, Alt FW. 2003. Histone H2AX: a dosage-dependent suppressor of oncogenic translocations and tumors. Cell 114: 359-370.

Bian C, Wu R, Cho K, Yu X. 2012. Loss of BRCA1-A complex function in RAP80 null tumor cells. PLoS One 7: e40406.

Bogliolo M, Lyakhovich A, Callen E, Castella M, Cappelli E, Ramirez MJ, Creus A, Marcos R, Kalb R, Neveling K, et al. 2007. Histone H2AX and Fanconi anemia FANCD2 function in the same pathway to maintain chromosome stability. $E M B O$ I 26: 1340-1351.

Bouwman P, Aly A, Escandell JM, Pieterse M, Bartkova J, van der Gulden H, Hiddingh S, Thanasoula M, Kulkarni A, Yang Q, et al. 2010. 53BP1 loss rescues BRCA1 deficiency and is associated with triple-negative and BRCA-mutated breast cancers. Nat Struct Mol Biol 17: 688-695.

Bunting SF, Callen E, Wong N, Chen HT, Polato F, Gunn A, Bothmer A, Feldhahn N, Fernandez-Capetillo O, Cao L, et al. 2010. 53BP1 inhibits homologous recombination in Brcal-deficient cells by blocking resection of DNA breaks. Cell 141: 243-254.

Cao L, Xu X, Bunting SF, Liu J, Wang RH, Cao LL, Wu JJ, Peng TN, Chen J, Nussenzweig A, et al. 2009. A selective requirement for 53BP1 in the biological response to genomic instability induced by Brcal deficiency. Mol Cell 35: 534-541.

Celeste A, Petersen S, Romanienko PJ, Fernandez-Capetillo O, Chen HT, Sedelnikova OA, Reina-San-Martin B, Coppola V, Meffre E, Difilippantonio MJ, et al. 2002. Genomic instability in mice lacking histone H2AX. Science 296: 922-927.

Celeste A, Fernandez-Capetillo O, Kruhlak MJ, Pilch DR, Staudt DW, Lee A, Bonner RF, Bonner WM, Nussenzweig A. 2003. Histone H2AX phosphorylation is dispensable for the initial recognition of DNA breaks. Nat Cell Biol 5: 675-679.

Chen X, Arciero CA, Wang C, Broccoli D, Godwin AK. 2006. BRCC36 is essential for ionizing radiation-induced BRCA1 phosphorylation and nuclear foci formation. Cancer Res 66: 5039-5046.

Chen W, Alpert A, Leiter C, Gong F, Jackson SP, Miller KM. 2013. Systematic identification of functional residues in mammalian histone H2AX. Mol Cell Biol 33: 111-126.

Ciccia A, Elledge SJ. 2010. The DNA damage response: making it safe to play with knives. Mol Cell 40: 179-204.

Coleman KA, Greenberg RA. 2011. The BRCA1-RAP80 complex regulates DNA repair mechanism utilization by restricting end resection. J Biol Chem 286: 13669-13680.

Curtin NJ. 2012. DNA repair dysregulation from cancer driver to therapeutic target. Nat Rev Cancer 12: 801-817. 
Feng L, Huang J, Chen J. 2009. MERIT40 facilitates BRCA1 localization and DNA damage repair. Genes Dev 23: 719-728.

Fradet-Turcotte A, Canny MD, Escribano-Diaz C, Orthwein A, Leung CC, Huang H, Landry MC, Kitevski-LeBlanc J, Noordermeer SM, Sicheri F, et al. 2013. 53BP1 is a reader of the DNA-damage-induced H2A Lys 15 ubiquitin mark. Nature 499: $50-54$.

Gong F, Chiu LY, Cox B, Aymard F, Clouaire T, Leung JW, Cammarata M, Perez M, Agarwal P, Brodbelt JS, et al. 2015. Screen identifies bromodomain protein ZMYND8 in chromatin recognition of transcription-associated DNA damage that promotes homologous recombination. Genes Dev 29: 197-211.

Gunn A, Bennardo N, Cheng A, Stark JM. 2011. Correct end use during end joining of multiple chromosomal double strand breaks is influenced by repair protein RAD50, DNA-dependent protein kinase DNA-PKcs, and transcription context. $I$ Biol Chem 286: 42470-42482.

Hakimi MA, Dong Y, Lane WS, Speicher DW, Shiekhattar R. 2003. A candidate $X$-linked mental retardation gene is a component of a new family of histone deacetylase-containing complexes. J Biol Chem 278: 7234-7239.

Helfricht A, Wiegant WW, Thijssen PE, Vertegaal AC, Luijsterburg MS, van Attikum H. 2013. Remodeling and spacing factor 1 (RSF1) deposits centromere proteins at DNA doublestrand breaks to promote non-homologous end-joining. Cell Cycle 12: 3070-3082.

Helmink BA, Tubbs AT, Dorsett Y, Bednarski JJ, Walker LM, Feng Z, Sharma GG, McKinnon PJ, Zhang J, Bassing CH, et al. 2011. H2AX prevents CtIP-mediated DNA end resection and aberrant repair in G1-phase lymphocytes. Nature 469: 245-249.

Hu X, Kim JA, Castillo A, Huang M, Liu J, Wang B. 2011a. NBA1/ MERIT40 and BRE interaction is required for the integrity of two distinct deubiquitinating enzyme BRCC36-containing complexes. J Biol Chem 286: 11734-11745.

Hu Y, Scully R, Sobhian B, Xie A, Shestakova E, Livingston DM. 2011b. RAP80-directed tuning of BRCA1 homologous recombination function at ionizing radiation-induced nuclear foci. Genes Dev 25: 685-700.

Huether R, Dong L, Chen X, Wu G, Parker M, Wei L, Ma J, Edmonson MN, Hedlund EK, Rusch MC, et al. 2014. The landscape of somatic mutations in epigenetic regulators across 1,000 paediatric cancer genomes. Nat Commun 5: 3630.

Jackson SP, Bartek J. 2009. The DNA-damage response in human biology and disease. Nature 461: 1071-1078.

Kalb R, Mallery DL, Larkin C, Huang JT, Hiom K. 2014. BRCA1 is a histone-H2A-specific ubiquitin ligase. Cell Rep 8: 999-1005.

Khurana S, Kruhlak MJ, Kim J, Tran AD, Liu J, Nyswaner K, Shi L, Jailwala P, Sung MH, Hakim O, et al. 2014. A macrohistone variant links dynamic chromatin compaction to BRCA1-dependent genome maintenance. Cell Rep 8: 1049-1062.

Kim H, Chen J, Yu X. 2007a. Ubiquitin-binding protein RAP80 mediates BRCA1-dependent DNA damage response. Science 316: 1202-1205.

Kim H, Huang J, Chen J. 2007b. CCDC98 is a BRCA1-BRCT domain-binding protein involved in the DNA damage response. Nat Struct Mol Biol 14: 710-715.

Kojima KK, Jurka J. 2011. Crypton transposons: identification of new diverse families and ancient domestication events. Mob DNA 2: 12.

Kouzarides T. 2007. Chromatin modifications and their function. Cell 128: 693-705.

Lee MS, Edwards RA, Thede GL, Glover JN. 2005. Structure of the BRCT repeat domain of $\mathrm{MDC} 1$ and its specificity for the free
$\mathrm{COOH}$-terminal end of the $\gamma-\mathrm{H} 2 \mathrm{AX}$ histone tail. I Biol Chem 280: 32053-32056.

Leung JW, Wang Y, Fong KW, Huen MS, Li L, Chen J. 2012. Fanconi anemia (FA) binding protein FAAP20 stabilizes FA complementation group A (FANCA) and participates in interstrand cross-link repair. Proc Natl Acad Sci 109: 44914496.

Leung JW, Agarwal P, Canny MD, Gong F, Robison AD, Finkelstein IJ, Durocher D, Miller KM. 2014. Nucleosome acidic patch promotes RNF168- and RING1B/BMI1-dependent H2AX and H2A ubiquitination and DNA damage signaling. PLoS Genet 10: e1004178.

Li ML, Greenberg RA. 2012. Links between genome integrity and BRCA1 tumor suppression. Trends Biochem Sci 37: 418-424.

Lieber MR, Gu J, Lu H, Shimazaki N, Tsai AG. 2010. Nonhomologous DNA end joining (NHEJ) and chromosomal translocations in humans. Subcell Biochem 50: 279-296.

Liu Z, Wu J, Yu X. 2007. CCDC98 targets BRCA1 to DNA damage sites. Nat Struct Mol Biol 14: 716-720.

Luger K, Mader AW, Richmond RK, Sargent DF, Richmond TJ. 1997. Crystal structure of the nucleosome core particle at 2.8 A resolution. Nature 389: 251-260.

Makharashvili N, Tubbs AT, Yang SH, Wang H, Barton O, Zhou Y, Deshpande RA, Lee JH, Lobrich M, Sleckman BP, et al. 2014. Catalytic and noncatalytic roles of the CtIP endonuclease in double-strand break end resection. Mol Cell 54: 1022-1033.

Miller KM, Jackson SP. 2012. Histone marks: repairing DNA breaks within the context of chromatin. Biochem Soc Trans 40: 370-376.

Ng HM, Wei L, Lan L, Huen MS. 2016. The Lys63-deubiquitylating enzyme BRCC36 limits DNA break processing and repair. I Biol Chem 291: 16197-16207.

Nikkila J, Coleman KA, Morrissey D, Pylkas K, Erkko H, Messick TE, Karppinen SM, Amelina A, Winqvist R, Greenberg RA. 2009. Familial breast cancer screening reveals an alteration in the RAP80 UIM domain that impairs DNA damage response function. Oncogene 28: 1843-1852.

Paull TT, Rogakou EP, Yamazaki V, Kirchgessner CU, Gellert M, Bonner WM. 2000. A critical role for histone H2AX in recruitment of repair factors to nuclear foci after DNA damage. Curr Biol 10: 886-895.

Polo SE, Jackson SP. 2011. Dynamics of DNA damage response proteins at DNA breaks: a focus on protein modifications. Genes Dev 25: 409-433.

Puente XS, Bea S, Valdes-Mas R, Villamor N, Gutierrez-Abril J, Martin-Subero JI, Munar M, Rubio-Perez C, Jares P, Aymerich $M$, et al. 2015. Non-coding recurrent mutations in chronic lymphocytic leukaemia. Nature 526: 519-524.

Ran FA, Hsu PD, Wright J, Agarwala V, Scott DA, Zhang F. 2013. Genome engineering using the CRISPR-Cas9 system. Nat Protoc 8: 2281-2308.

Robinson G, Parker M, Kranenburg TA, Lu C, Chen X, Ding L, Phoenix TN, Hedlund E, Wei L, Zhu X, et al. 2012. Novel mutations target distinct subgroups of medulloblastoma. Nature 488: 43-48.

Rogakou EP, Pilch DR, Orr AH, Ivanova VS, Bonner WM. 1998. DNA double-stranded breaks induce histone $\mathrm{H} 2 \mathrm{AX}$ phosphorylation on serine 139. J Biol Chem 273: 5858-5868.

Rogakou EP, Boon C, Redon C, Bonner WM. 1999. Megabase chromatin domains involved in DNA double-strand breaks in vivo. J Cell Biol 146: 905-916.

Shao G, Patterson-Fortin J, Messick TE, Feng D, Shanbhag N, Wang Y, Greenberg RA. 2009. MERIT40 controls BRCA1- 
Rap80 complex integrity and recruitment to DNA doublestrand breaks. Genes Dev 23: 740-754.

Shevchenko A, Tomas H, Havlis J, Olsen JV, Mann M. 2006. Ingel digestion for mass spectrometric characterization of proteins and proteomes. Nat Protoc 1: 2856-2860.

Sobhian B, Shao G, Lilli DR, Culhane AC, Moreau LA, Xia B, Livingston DM, Greenberg RA. 2007. RAP80 targets BRCA1 to specific ubiquitin structures at DNA damage sites. Science 316: 1198-1202.

Sonoda E, Zhao GY, Kohzaki M, Dhar PK, Kikuchi K, Redon C, Pilch DR, Bonner WM, Nakano A, Watanabe M, et al. 2007. Collaborative roles of $\gamma \mathrm{H} 2 \mathrm{AX}$ and the Rad51 paralog Xrcc3 in homologous recombinational repair. DNA Repair (Amst) 6: $280-292$.

Stucki M, Jackson SP. 2006. $\gamma \mathrm{H} 2 \mathrm{AX}$ and MDC1: anchoring the DNA-damage-response machinery to broken chromosomes. DNA Repair (Amst) 5: 534-543.

Stucki M, Clapperton JA, Mohammad D, Yaffe MB, Smerdon SJ, Jackson SP. 2005. MDC1 directly binds phosphorylated histone H2AX to regulate cellular responses to DNA doublestrand breaks. Cell 123: 1213-1226.

Tang J, Cho NW, Cui G, Manion EM, Shanbhag NM, Botuyan MV, Mer G, Greenberg RA. 2013. Acetylation limits 53BP1 association with damaged chromatin to promote homologous recombination. Nat Struct Mol Biol 20: 317-325.

Taverna SD, Li H, Ruthenburg AJ, Allis CD, Patel DJ. 2007. How chromatin-binding modules interpret histone modifications: lessons from professional pocket pickers. Nat Struct Mol Biol 14: 1025-1040.

Tirode F, Surdez D, Ma X, Parker M, Le Deley MC, Bahrami A, Zhang Z, Lapouble E, Grossetete-Lalami S, Rusch M, et al. 2014. Genomic landscape of Ewing sarcoma defines an aggressive subtype with co-association of STAG2 and TP53 mutations. Cancer Discov 4: 1342-1353.

van der Maarel SM, Scholten IH, Huber I, Philippe C, Suijkerbuijk RF, Gilgenkrantz S, Kere J, Cremers FP, Ropers HH. 1996. Cloning and characterization of DXS6673E, a candidate gene for X-linked mental retardation in Xq13.1. Hum Mol Genet 5: 887-897.

Wang B, Matsuoka S, Ballif BA, Zhang D, Smogorzewska A, Gygi SP, Elledge SJ. 2007. Abraxas and RAP80 form a BRCA1 pro- tein complex required for the DNA damage response. Science 316: 1194-1198.

Wang B, Hurov K, Hofmann K, Elledge SJ. 2009. NBA1, a new player in the Brcal A complex, is required for DNA damage resistance and checkpoint control. Genes Dev 23: 729-739.

Wang L, Lawrence MS, Wan Y, Stojanov P, Sougnez C, Stevenson K, Werner L, Sivachenko A, DeLuca DS, Zhang L, et al. 2011. SF3B1 and other novel cancer genes in chronic lymphocytic leukemia. N Engl J Med 365: 2497-2506.

Wilson MD, Benlekbir S, Fradet-Turcotte A, Sherker A, Julien JP, McEwan A, Noordermeer SM, Sicheri F, Rubinstein JL, Durocher D. 2016. The structural basis of modified nucleosome recognition by 53BP1. Nature 536: 100-103.

Wu J, Huen MS, Lu LY, Ye L, Dou Y, Ljungman M, Chen J, Yu $\mathrm{X}$. 2009. Histone ubiquitination associates with BRCA1dependent DNA damage response. Mol Cell Biol 29: 849860.

Wu J, Liu C, Chen J, Yu X. 2012. RAP80 protein is important for genomic stability and is required for stabilizing BRCA1-A complex at DNA damage sites in vivo. I Biol Chem 287: 22919-22926.

Xie A, Puget N, Shim I, Odate S, Jarzyna I, Bassing CH, Alt FW, Scully R. 2004. Control of sister chromatid recombination by histone H2AX. Mol Cell 16: 1017-1025.

Xie A, Hartlerode A, Stucki M, Odate S, Puget N, Kwok A, Nagaraju G, Yan C, Alt FW, Chen J, et al. 2007. Distinct roles of chromatin-associated proteins $\mathrm{MDC} 1$ and 53BP1 in mammalian double-strand break repair. Mol Cell 28: 1045-1057.

Xu C, Xu Y, Gursoy-Yuzugullu O, Price BD. 2012a. The histone variant macroH2A1.1 is recruited to DSBs through a mechanism involving PARP1. FEBS Lett 586: 3920-3925.

Xu Y, Ayrapetov MK, Xu C, Gursoy-Yuzugullu O, Hu Y, Price BD. 2012b. Histone H2A.Z controls a critical chromatin remodeling step required for DNA double-strand break repair. Mol Cell 48: 723-733.

Zha S, Guo C, Boboila C, Oksenych V, Cheng HL, Zhang Y, Wesemann DR, Yuen G, Patel H, Goff PH, et al. 2011. ATM damage response and XLF repair factor are functionally redundant in joining DNA breaks. Nature 469: 250-254. 


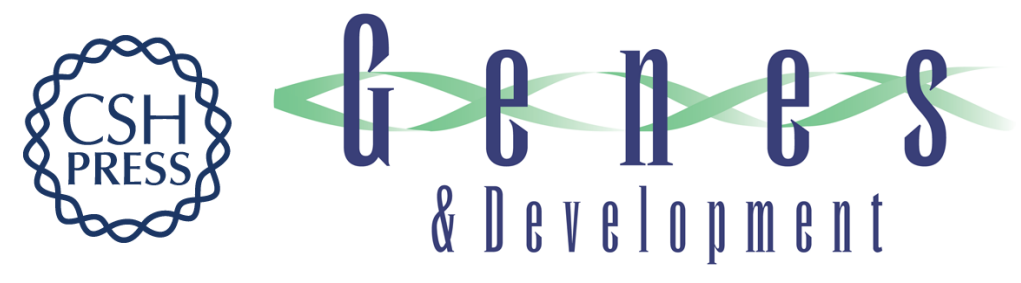

\section{ZMYM3 regulates BRCA1 localization at damaged chromatin to promote DNA repair}

Justin W.C. Leung, Nodar Makharashvili, Poonam Agarwal, et al.

Genes Dev. 2017, 31: originally published online February 27, 2017

Access the most recent version at doi:10.1101/gad.292516.116

\section{Supplemental http://genesdev.cshlp.org/content/suppl/2017/02/27/gad.292516.116.DC1 \\ Material}

References This article cites 72 articles, 27 of which can be accessed free at: http://genesdev.cshlp.org/content/31/3/260.full.html\#ref-list-1

Creative This article is distributed exclusively by Cold Spring Harbor Laboratory Press for the first Commons six months after the full-issue publication date (see

License http://genesdev.cshlp.org/site/misc/terms.xhtml). After six months, it is available under a Creative Commons License (Attribution-NonCommercial 4.0 International), as described at http://creativecommons.org/licenses/by-nc/4.0/.

Email Alerting Receive free email alerts when new articles cite this article - sign up in the box at the top Service right corner of the article or click here.

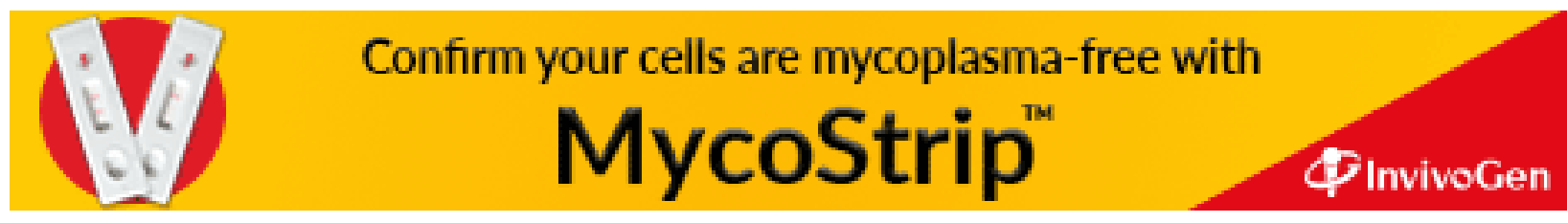

